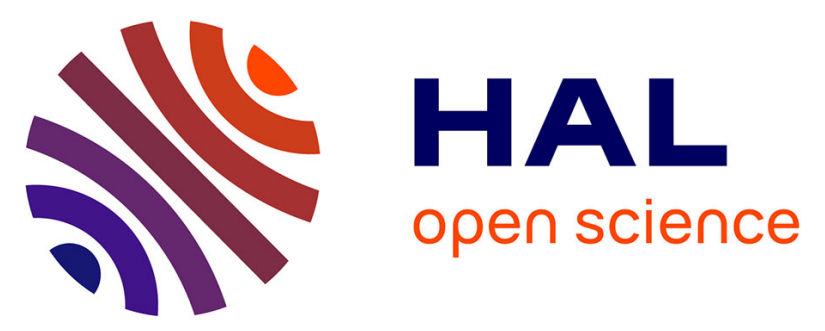

\title{
Adjacent woodlands rather than habitat connectivity influence grassland plant, carabid and bird assemblages in farmland landscapes
}

Rémi Duflot, Hervé Daniel, Stéphanie Aviron, Audrey Alignier, Véronique Beaujouan, Francoise Burel, Arnaud Cochard, Aude Ernoult, Guillaume Pain, Joséphine A. Pithon

\section{To cite this version:}

Rémi Duflot, Hervé Daniel, Stéphanie Aviron, Audrey Alignier, Véronique Beaujouan, et al.. Adjacent woodlands rather than habitat connectivity influence grassland plant, carabid and bird assemblages in farmland landscapes. Biodiversity and Conservation, 2018, 27 (8), pp.1925-1942. 10.1007/s10531018-1517-y . hal-01832710

HAL Id: hal-01832710

https://hal-univ-rennes1.archives-ouvertes.fr/hal-01832710

Submitted on 12 Sep 2018

HAL is a multi-disciplinary open access archive for the deposit and dissemination of scientific research documents, whether they are published or not. The documents may come from teaching and research institutions in France or abroad, or from public or private research centers.
L'archive ouverte pluridisciplinaire HAL, est destinée au dépôt et à la diffusion de documents scientifiques de niveau recherche, publiés ou non, émanant des établissements d'enseignement et de recherche français ou étrangers, des laboratoires publics ou privés. 
1 Authors:

2 Duflot Rémi ${ }^{\mathrm{a}^{*}}$, Daniel Hervé ${ }^{\mathrm{a}}$, Aviron Stéphanie ${ }^{\mathrm{b}}$, Alignier Audrey ${ }^{\mathrm{b}}$, Beaujouan Véronique $^{\mathrm{a}}$, Burel

3 Françoise $^{\mathrm{c}}$, Cochard Arnaud ${ }^{\mathrm{a}}$, Ernoult Aude ${ }^{\mathrm{c}}$, Pain Guillaume ${ }^{\mathrm{a}}$, Pithon Joséphine A. ${ }^{\mathrm{a}}$

4

5 Title:

6 Adjacent woodlands rather than habitat connectivity influence grassland plant, carabid and bird

$7 \quad$ assemblages in farmland landscapes

8

9 Affiliations:

10

${ }^{a}$ BAGAP, INRA, Agrocampus Ouest, ESA, Angers, France

11

${ }^{\mathrm{b}}$ BAGAP, INRA, Agrocampus Ouest, ESA, Rennes, France

12

${ }^{\mathrm{c}}$ Ecobio, CNRS, Université de Rennes 1, Rennes, France

13

14

* Corresponding author

15

Duflot Rémi

16

duflot.remi@gmail.com

$17+33645648673$

18

BAGAP, INRA, Agrocampus Ouest, ESA, 2 rue André Le Nôtre, 49045 Angers Cedex 01, France

19 
One response to biodiversity decline is the definition of ecological networks that extend beyond protected areas and promote connectivity in human-dominated landscapes. In farmland, landscape ecological research has focused more on wooded than open habitat networks. In our study, we assessed the influence of permanent grassland connectivity, described by grassland amount and spatial configuration, on grassland biodiversity. We selected permanent grasslands in livestock farming areas of north-western France, which were sampled for plants, carabids and birds. At two spatial scales we tested the effects of amount and configuration of grasslands, wooded habitats and crops on richness and abundance of total assemblages and species ecological groups. Grassland connectivity had no significant effects on total richness or abundance of any taxonomic group, regardless of habitat affinity or dispersal ability. The amount of wooded habitat and length of wooded edges at the $200 \mathrm{~m}$ scale positively influenced forest and generalist animal groups as well as grassland plant species, in particular animal-dispersed species. However, for animal groups such as open habitat carabids or farmland bird specialists, the same wooded habitats negatively influenced richness and abundance at the $500 \mathrm{~m}$ scale. The scale and direction of biodiversity responses to landscape context were therefore similar among taxonomic groups, but opposite for habitat affinity groups. We conclude that while grassland connectivity is unlikely to contribute positively to biodiversity, increasing or maintaining wooded elements near grasslands would be a worthwhile conservation goal. However, the requirements of open farmland animal species groups must be considered, for which such action may be deleterious.

\section{Key words}

Multi-taxon biodiversity; habitat network; random forests; multi-model inference; dispersal; hedgerow; human-dominated landscapes 


\section{$45 \quad$ Highlights}

46 Permanent grassland connectivity had little effect on biodiversity

47 Wooded habitats in the landscape influenced grassland plants, carabids and birds

48 Open habitat animal specialists avoided landscapes with woods and hedgerows

49 Response to landscape was more dependent on habitat affinity than on taxonomic group

50 Increasing or maintaining wooded elements near grasslands may be good policy

51 


\section{Introduction}

In human-dominated, highly fragmented landscapes, site protection alone is unlikely to achieve the objective of stopping or reversing biodiversity declines (Bennett and Saunders 2010). Rather enhancing habitat connectivity or linkages, such as ecological corridors and networks, will be needed to ensure the viability of plant and animal populations (Crooks and Sanjayan 2006). This connectivity depends on the amount (area) and spatial configuration of suitable habitat as well as on matrix permeability (Bennett 2003). Nature conservation policy has accordingly evolved towards the implementation of habitat networks (ecological networks or greenveining), which are increasingly integrated into international, national or regional planning; particularly in Europe (Boitani et al. 2007; Jongman et al. 2011). For example, since 2009 in France, it has become a legal requirement that habitat networks be established at national, regional and local levels (Vanpeene-Bruhier and Amsallem, 2014). Most territory may potentially be concerned by this policy's implementation, including areas subject to more or less intense human activity. The need to develop nature conservation outside protected areas has been accompanied by the recognition that most conservation efforts have tended to focus on rare species and habitats, sometimes to the detriment of common biodiversity (Inger et al. 2015). However, such biodiversity dominates ecosystem composition and makes an important contribution to ecosystem functioning (Gaston and Fuller 2008; Gaston 2008).

Agriculture is clearly one of the major human activities to be concerned by these shifts in policy. Farming landscapes occupy large areas of land (approximatively 75\% in Europe, Robinson and Sutherland 2002, and up to $40 \%$ globally, Foley et al. 2005) and are associated with a valuable and partly typical flora and fauna (Benton et al. 2003), which has declined severely over the past few decades (Chamberlain et al. 2000; Donald et al. 2001; Liira et al. 2008). There is some consensus on the importance of landscape complexity, or the amount of semi-natural habitat, in determining levels of biodiversity in farmland landscapes (Benton et al. 2003; Tscharntke et al. 2012). In this context, attempts are being made to preserve and enhance semi-natural habitats of ecological value, like hedgerows and permanent grasslands. These habitats have generally diminished (Meeus 1993) and are 
the focus of some considerable attention in the context of nature conservation in farming areas. For instance, in France permanent grasslands declared by farmers represented 6.7 million ha of agricultural land at national scale in 2006. By $20106.3 \%$ of them had been lost, replaced by temporary grasslands or scrubland (Faïq et al. 2013). Enhanced connectivity of these semi-natural habitats is expected to counteract the negative effects of such reductions in biodiversity (e.g. Hendrickx et al. 2007).

Studies of connectivity effects in farmland contexts have tended to focus on wooded habitat types (e.g. Gil-Tena et al. 2014; Neumann et al. 2016). The effectiveness of linear woodland habitats, like hedgerows, as corridors facilitating forest specialist dispersal has been demonstrated for a diversity of taxonomic groups: birds (Davies and Pullin 2007), arthropods (e.g. carabid beetles, Petit 1994; MillanPena et al. 2003), plants (Jamoneau et al. 2011) and small mammals (Gelling et al. 2007). Meanwhile the possible effects of increasing permanent grassland connectivity for farmland biodiversity have received relatively less attention. Most studies of grassland connectivity have concentrated on rarer grasslands of high conservation value, such as wet grasslands (e.g. Lafage et al. 2015), calcareous grasslands (e.g. Brückmann et al. 2010; Rösch et al. 2013), heathland (e.g. Piessens et al. 2005), species-rich grasslands at higher altitudes (e.g. Marini et al. 2008) or indigenous grasslands fragmented by commercial forestry (e.g. Samways \& Pryke, 2016). These studies, involving a diversity of taxonomic groups, have shown that species of open, grassland habitats may respond positively to increasing grassland connectivity. Common permanent grasslands of agricultural mosaics, which are mesophilic, managed grasslands that have not been ploughed for several years, have been understudied in landscape connectivity research. With their lack of vertical heterogeneity and dependence on highly variable forms of management, such grasslands are difficult to describe (Allen et al. 2011) and until the recent focus on common biodiversity may have been expected to harbour few species of conservation interest. Only a few studies in Europe have begun to explore how connectivity of more managed grasslands may influence arthropods and plant assemblages (Öckinger et al. 2012; Wamser et al. 2012; Villemey et al. 2015). These studies found contrasting effects of grassland connectivity on species richness. Thus, it is important to further explore to what extent 
connectivity of common permanent grassland contributes to maintaining biodiversity in farmland mosaics.

The effects of landscape context depend on the varying scales of perception of taxa with differing dispersal abilities (Jackson and Fahrig 2012) and within-taxa differences in dispersal ability may potentially obscure the effects of connectivity at assemblage level (e.g. Wamser et al. 2012). In addition, species with different habitat affinities may display opposing responses to landscape structure (Mauremooto et al. 1995; Thomas et al. 1998; Filippi-Codaccioni et al. 2010). Therefore, using two spatial scales, we aimed to assess how variation in grassland connectivity (amount and spatial configuration) influenced the richness and abundance of various taxonomic groups with potentially different scales of landscape perception: plants, carabids and birds observed in common, mesophilic, permanent grasslands. We hypothesized that grassland connectivity would increase richness and / or abundance of these assemblages. We also looked at the richness and abundance of species groups based on habitat affinity and dispersal ability, and compared the influence of grasslands with that of wooded habitats and crops in the surrounding landscape. We further hypothesized that grassland specialist or open habitat species would benefit most from grassland connectivity or amount of crops. Wooded habitats (particularly hedgerows) may act as barriers for these species, while they may help forest species to disperse and therefore increase richness and abundance of this group in grasslands. We expected a stronger influence of landscape structure on species with low dispersal ability.

\section{Method}

2.1. Study areas and permanent grassland selection The study was conducted in north-western France, where farmland landscapes contain annual crops (mostly winter cereals, but also spring maize and oilseed rape), along with temporary and permanent grasslands (not ploughed for at least 5 years), separated by woodland and hedgerow networks (which 
La-Roche-sur-Yon and Rennes which shared the same climate (temperate oceanic), geo-morphological conditions (acidic substrate: schists, granites, sandstones) and a similar agricultural history of mixed dairy farming systems (Appendix 1A). In these areas, we selected permanent grasslands to maximize variation in the proportion of permanent grassland in the surrounding landscape. These production grasslands were originally established by farmers, using a mixture of sown species of grasses and sometimes clover, but most plant species were native. In western Europe and elsewhere, such grasslands have a long history of agricultural management, and their biodiversity has long been determined by the dynamics of regular mowing and grazing. To minimise other sources of variation, we excluded wet grassland and grasslands that were close to major roads or urban infrastructure. All were grazed, as this factor is known to have a strong influence on grassland plant assemblages (Gaujour et al., 2012).

\subsection{Sampling and biodiversity measures}

Biodiversity was sampled in between 21 and 55 permanent grasslands, depending on taxonomic group. The proportion of grassland in the landscape surrounding sampled grasslands (200m-radius buffer) ranged from 12 to $85 \%$ for plant, from 10 to $58 \%$ for carabids and 28 to $85 \%$ for birds. Plants were sampled in 55 permanent grasslands (4 Nantes, 18 Angers, 14 La Roche-sur-Yon, 19 Rennes). Each grassland was visited once between 2011 and 2015, in the late spring or summer (May -July). All vascular species were listed within 3 quadrats of $2 \times 2 \mathrm{~m}$ per grassland, placed at least $2 \mathrm{~m}$ from the field edge, and these were subsequently pooled for calculation of species richness measures.

Carabid beetles were sampled in 40 permanent grasslands (40 Rennes), using pitfall traps. Two pitfall traps per grassland were located $1 \mathrm{~m}$ from each other and $10 \mathrm{~m}$ from grassland edge. Carabids were sampled during six sampling periods, two per month in May, June and September 2011, to coincide with the seasons during which carabid beetles emerge (spring and late summer). Traps were collected every two weeks, after being open for seven consecutive days. Eliminating a few lost traps (destroyed by cattle), we measured activity-density as the number of individuals per trap per week and we 
checked that the number of valid traps did not influence species richness. The six sampling periods were then pooled to calculate species richness and activity-density measures for each grassland.

Birds were sampled in 21 permanent grasslands (10 Angers, 11 La Roche-sur-Yon) and their associated field margin vegetation, using standard territory mapping (Bibby et al. 2000). The grasslands were visited six times per breeding season in 2014 and 2015 (between mid-March and midJune). All bird surveys were carried out by a single observer between 1 and 4 hours after sunrise, on days without continuous rain or wind. Species defending one or more territories in at least one of the two years were considered to be breeding birds. The two years were pooled for calculation of species richness measures while abundance values corresponded to the maximum number of territories a species defended over the two years.

Plants, carabids and birds were classified according to their habitat affinity (generalists, grassland or open farmland specialists, woodland specialists) or to their dispersal ability (dispersal mode for plants, wing system for carabids and a morphological dispersal ability predictor for birds; see below). Species richness and abundance (for carabids and birds) were calculated for each habitat affinity or dispersal ability group. Plant ecological preferences were adapted from Baseflor database (Julve, 1998) and plant dispersal mode extracted from Biolflor (Kuhn et al. 2004) and Baseflor (Julve 1998) databases (Appendix 1B). Carabid habitat affinity data were adapted from Neumann et al. (2016) and Roger et al. (2010). Carabid species dispersal ability was estimated by the wing system (Kotze and O'Hara 2003; Purtauf et al. 2004) using information from Barbaro and van Halder (2009), Ribera et al. (2001), and BETSI database (2012, Appendix 1C). Bird habitat affinity groups were based on analysis of national bird monitoring data (Jiguet 2010) except for 14 missing species, for which we used regional atlas descriptions of habitat use (Marchadour 2014). Bird dispersal ability was estimated by using the quotient of Kipp's distance (distance between the tip of the first primary feather to the tip of the wing) and bill depth (measured at the proximate edge of the nostrils), which has been shown to be a good surrogate for natal dispersal distance in European passerines (Dawideit et al. 2009). Biometric data were provided by the Senckenberg Biodiversity and Climate Research Centre in Frankfurt, Germany 
(for details, see Laube et al. 2013). Based on the obtained dispersal ability predictor we classified birds into 4 dispersal categories (low, medium, high and long distance) using Jenks natural breaks (Appendix 1D). Some bird ecological groups containing very few species, at low levels of frequency or abundance, were excluded from analysis (urban species and long-distance dispersers).

\subsection{Land-cover maps and landscape descriptors}

We produced land-cover maps of the four study areas using existing land cover databases coupled with automatic classification of satellite imagery, and corrected by photo-interpretation and groundtruthing. Land-cover classification was as follows: built-up area (roads and buildings), water bodies, crop fields, permanent grasslands, and wooded habitats (woodland and hedgerows). We paid particular attention to the accurate estimation of permanent grassland distribution, using photo-interpretation and the Land Parcel Identification System (i.e. Registre Parcellaire Graphique), where farmers subsidised by the Common Agricultural Policy (CAP) declare field use. These maps were produced using QGIS (QGIS Development Team, 2015).

Landscape descriptors were calculated from these maps within $200 \mathrm{~m}$ and $500 \mathrm{~m}$ radius, circular buffers centred on each sampled grassland, in order to describe two components of the connectivity of permanent grassland, i.e. grassland amount and grassland configuration. These circular buffers were centred on field centroids for plants and birds, or on exact trap locations for carabids (recorded with a GPS). The choice of two spatial scales was to account for expected differing grains of landscape perception between plants, carabids and birds (Jackson and Fahrig, 2012). Amount of permanent grassland was described as the proportion of surface area covered by these habitats in buffers.

Configuration of permanent grassland was assessed via three contrasting landscape descriptors, chosen to investigate the possible influence of different forms of spatial arrangement: largest grassland patch area, length of permanent grassland edges and a grassland connectivity index (derived from Hanski 1999, see Steffan-Dewenter 2003):

$C_{k}=\sum_{i}^{n} e^{-D_{i k}} A_{i}$ 
where $k$ is the focal sampled permanent grassland, $n$ the number of other (non-sampled) permanent grasslands in the $200 \mathrm{~m}$ or $500 \mathrm{~m}$ scale landscape, $D_{i k}$ is the distance between the sampled grasslands $k$

217 and the neighbouring permanent grassland $i$ and $A_{i}$ the area of the neighbouring permanent grassland $i$. This measure of connectivity increases when many, large, permanent grasslands are located near the sampled grassland. The proportion of other main habitat types was also calculated for the two buffer sizes: wooded habitat (woodlands + hedgerows), and crops (including temporary grasslands which are part of crop rotations). Total length of wooded habitat edges was also measured as it reflects fragmentation of open habitats and adjacencies between open and wooded habitats. In the studied landscapes, wooded habitat edges mostly corresponded to the presence of hedgerows. Landscape descriptors were calculated at the two spatial scales using Chloe 2012 (Boussard and Baudry 2014). The extent of variation in each landscape descriptor, obtained at each scale and for each study taxon, is presented in Appendices 1E and 1F.

\subsection{Statistical analyses}

To test the representativeness of our sampled communities compared to potential richness, we calculated non-parametric species richness estimators of Chao2 across all grasslands (Chao, 1987). These estimated richness values were compared to the observed total number of species, for each taxon. We tested the effect of landscape descriptors on biodiversity measures using two successive steps (e.g. see Puech et al. 2014, Aviron et al. 2016): (i) preselection of landscape descriptors with random forest procedure, (ii) multi-model inference (MMI) and averaging of multiple regression models. Pearson's correlations between landscape descriptors and across scales are presented in Appendices 1G-I.

All seven landscape descriptors at both scales (14 variables) were included in a random forest analysis (Breiman 2001; Strobl et al. 2009), a recursive partitioning method recommended to deal with "small n large p problems" (i.e. few replicates and many environmental variables), complex interactions and correlated environmental variables (Strobl et al. 2008). For each biodiversity measure, 10,000 trees were grown and landscape descriptor importance was evaluated as the difference in model accuracy 
before and after 10 permutations of values of the considered descriptor, averaged over all trees.

244 Conditional importance that adjusts for correlations between environmental variables was used. The absolute importance value of the lowest negative-scoring landscape descriptor was used as a threshold to determine relevant and informative variables to retain for regression models (for full details, see Strobl et al. 2008, 2009). Landscape descriptors selected for each biodiversity measure may be found in Appendices 1J-L. To assess the influence of landscape descriptors on the global assemblage, the conditional importance values of each variable were averaged across the biodiversity measures for each taxon.

The selected landscape descriptors were then included in multiple regression models, which was analysed using multi-model inference (MMI) and model averaging. MMI analysis deals with model selection uncertainty (Burnham and Anderson 2002; Arnold 2010) and is robust against correlation among descriptors (Smith et al. 2009, 2011). All landscape descriptors were mean-centred and divided by the standard deviation to make the coefficients comparable (Smith et al. 2009, 2011). Following the MMI procedure, we created linear models for each possible combination of landscape descriptors and ranked them based on the corrected Akaike information criterion (AICc). Then, we computed standardised average regression coefficients weighted by the Akaike weights across supported best models $(\triangle \mathrm{AICc}<4)$ and tested their significance using unconditional $95 \%$ confidence intervals (Burnham and Anderson 2002; Smith et al. 2009, 2011). Averaged model coefficients and their $95 \%$ confidence intervals are presented in Appendices 1M-P. We also checked that the detected effects were consistent across all individual models included in model averaging (appendix 2). We more specifically looked at the correct estimation of relative effects of correlated landscape descriptors (grassland-related vs. wooded habitat descriptors, composition vs. configuration descriptors, and between scales).

Residuals of averaged models were tested for normality (Shapiro-Wilcoxon test and quantile-quantile plots) and spatial auto-correlation (Moran correlogram). When residuals were not normally distributed a new average model was built using the adequate distribution using a generalized linear model, either 
Poisson distribution for non-overdispersed data or negative binomial distribution for overdispersed

272

273

274

275

276

277 data (Crawley 2007; Bouche et al. 2009). No model showed spatial auto-correlation. Models included study area (plants and birds) or locality (carabids) as random factors (mixed models). All statistical tests were performed using R software 3.3.1 (R Core Team 2016) using the 'vegan' package for Chao2 estimation (Oksanen et al. 2013), the 'party' package for random forest analyses (Hothorn et al. 2013), the 'MuMin' package for MMI analyses (Barton 2016), and the 'lme4' package for generalized linear mixed-effects models (Bates et al. 2015), the 'qcc' package for over-dispersion testing (Scrucca 2004), and the 'ncf' package for spatial-autocorrelation test (Bjornstad 2016).

\section{Results}

In total, we sampled 108 plant species $($ Chao $2=125.0 \pm 8.2), 76$ carabid beetle species $($ Chao2 $=84.3$ $\pm 5.5,1922$ individuals) and 63 bird species $($ Chao $2=73.4 \pm 7.3), 41$ of which were breeding $($ Chao2 $=54.7 \pm 10.7,672$ breeding territories). Observed species richness was therefore close to expected for all taxonomic groups, indicating that the sampling intensity was adequate.

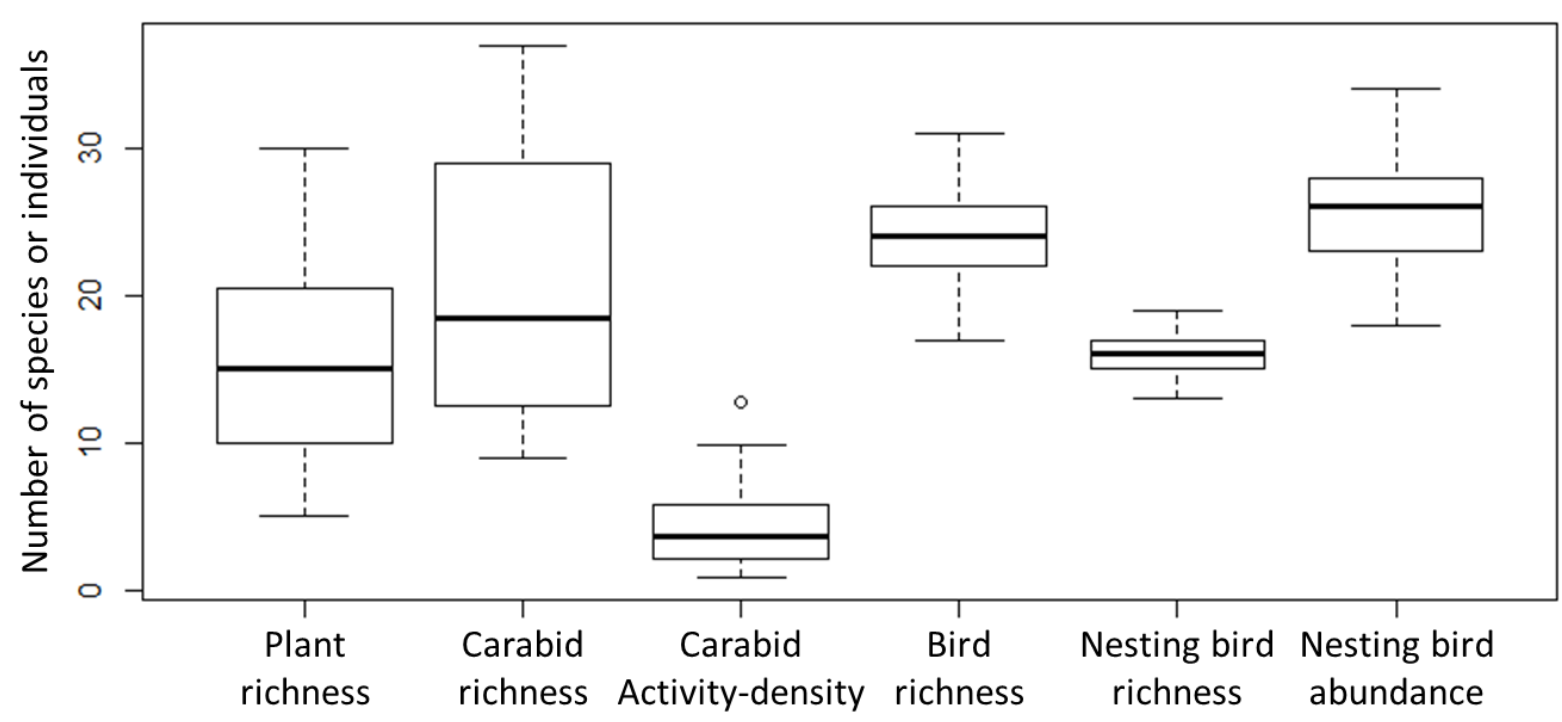

Figure 1. Boxplot of plant, carabid and bird biodiversity measures per sampled permanent grassland, all species included.

Measures of richness and abundance at the assemblage level varied between sampled permanent grasslands (Fig. 1), but could not be explained by permanent grassland connectivity. Proportion and spatial configuration descriptors of permanent grassland were sometimes selected by the random forest 
analysis, at both spatial scales, but they had limited explanatory power for carabid and bird

293

294

295

296

297

298

299

300

301

302

303

304

305

306

307

308

309

310

311

312

313

314

315

316

317

assemblages (Fig. 2). The only exception was largest grassland patch area at the $200 \mathrm{~m}$ scale for carabids, but this descriptor was selected only twice (Fig. 2). For plants, grassland-related descriptors were of higher importance than for the animal groups and were often selected, particularly the configuration descriptors at the $500 \mathrm{~m}$ scale (Fig. 2). However, they never significantly affected total species richness or activity-density / abundance of plants, carabids or birds (Appendices 1M-P). Nor did they have any significant influence on species richness or abundance measures of the different ecological groups, based on habitat affinity or dispersal ability. The only exception was a nearly significant negative effect of largest grassland patch area on total richness of forest bird specialists, at the $200 \mathrm{~m}$ scale (Appendix 1O). So, despite considerable variation in the amount and configuration of permanent grasslands across sampled grasslands (e.g. 10-80\% of permanent grassland for plants at the $200 \mathrm{~m}$ scale, Appendix 1E), these factors had little or no influence on the different taxonomic groups.

Plants

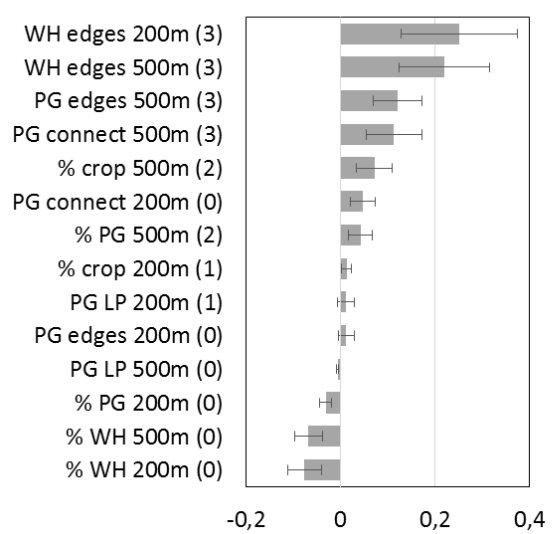

Carabids

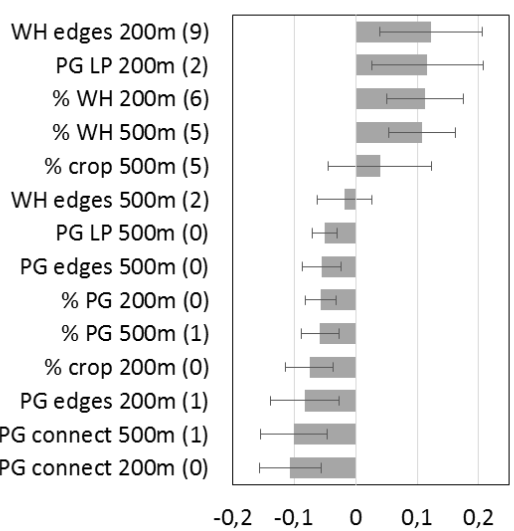

Birds

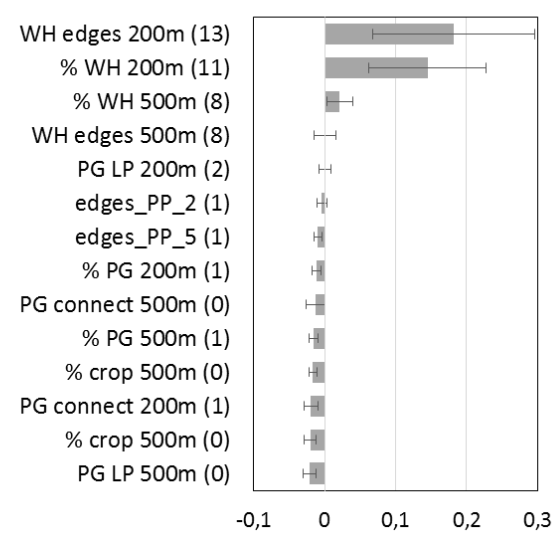

Figure 2. Conditional importance scores of landscape descriptors provided by random forest analyses, averaged across biodiversity measures for each studied taxon. Error bars are the standard errors. $n=7$ for plants, 16 for carabids and 21 for birds. In brackets are the number of times the considered landscape descriptor was selected by the random forest procedure. Detailed results on landscape descriptors selected for each biodiversity measure may be found in Appendices 1J-K. \% PG: proportion of permanent grassland (\%), PG connect: permanent grassland connectivity index, PG LP: largest permanent grassland patch (ha), PG edges: permanent grassland edges $(\mathrm{km}), \% \mathrm{WH}$ : proportion of wooded habitat $(\%)$, WH edges: wooded habitat edges ( $\mathrm{km})$, \% crops: proportion of crop (\%). "200m" and "500m" indicate the scale at which the considered landscape descriptor was measured.

Instead, the grassland assemblages of the three studied taxa were significantly influenced by wooded habitats. Random forest results showed that landscape descriptors related to wooded habitats were 
amongst those that explained the most variation in biodiversity measures, for the three taxa (Fig. 2).

319 Significant relationships between landscape descriptors and biodiversity measures are shown

320

321

322

323

324 graphically in Figures 3-5 and relationships that fell just short of the 95\% confidence level are also displayed, but without a trend line. The latter relationships are henceforth referred to as nearly significant (near. sig.). Wooded habitats had a particularly strong influence at the $200 \mathrm{~m}$ scale for birds and, to a lesser extent, carabid assemblages. Total plant species richness and richness of grassland plant specialists increased with increasing length of wooded habitat edges at the $200 \mathrm{~m}$ scale (Fig. $3 \mathrm{a} / \mathrm{b}$, Appendix 1M). These two biodiversity measures responded similarly as most plant species were grassland specialists (Appendix 1B). The length of wooded habitat edges significantly positively influenced animal-dispersed plant species richness at the $200 \mathrm{~m}$ scale and gravity-dispersed plant species richness (near.sig.), at the $500 \mathrm{~m}$ scale (Fig. 3c/d, Appendix 1M). Ruderal and wind-dispersed plant species were unaffected by landscape descriptors.
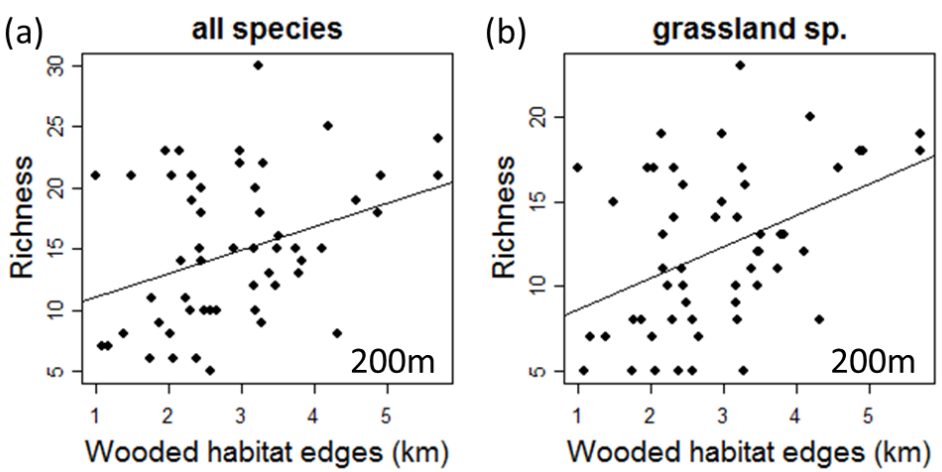

(c) zoochorous sp.

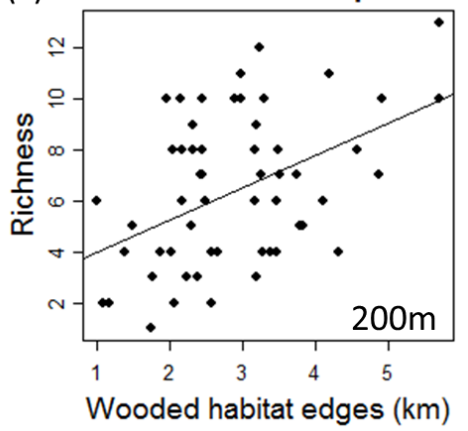

(d) barochorous sp.

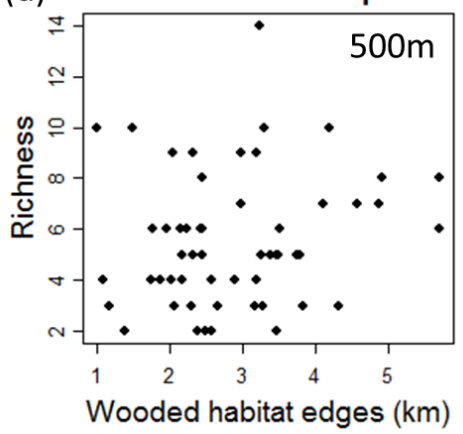

Figure 3. Graphical representation of significant and nearly significant results for plants biodiversity measures. Barochorous: gravity-dispersed, zoochorous: animal-dispersed. Scale of effects is indicated on each graph corner as the radius of buffers surrounding sampled permanent grasslands. Plain lines are given for illustrative purposes (only for significant results). Coefficients from average models are used for drawing linear and exponential lines (Appendix 1M). Linear lines are used for biodiversity measures analysed with Gaussian distribution. 
339 Total activity-density of carabid beetles tended to increase with increasing proportion of wooded

340 habitats (near.sig. Fig. 4a, Appendix 1N). Richness of open habitat carabids increased with increasing

341 proportion of crops area at the 500m scale (near. sig. Fig. 4b, Appendix 1N) which was strongly

342 negatively correlated with the proportion of wooded habitats at this scale $\left(\mathrm{r}_{\mathrm{S}}=-0.83\right.$, Appendix $\left.1 \mathrm{H}\right)$.

343 Species richness of forest carabid specialists increased with increasing length of wooded habitat edges

344 and activity-density of the same group significantly increased with increasing proportion of wooded

345 habitats, both at the 200m scale (Fig. 4c/d, Appendix 1N). Apterous carabid species, which are mostly

346 forest specialists (Appendix 1C), followed the same trends (near. sig. Fig. 4e/f, Appendix 1N).

347 Activity-density of carabid generalist and macropterous species were positively influenced by

348 increasing length of wooded habitat edges, also at the $200 \mathrm{~m}$ scale (Fig. $4 \mathrm{~g} / \mathrm{h}$, Appendix $1 \mathrm{~N})$. 

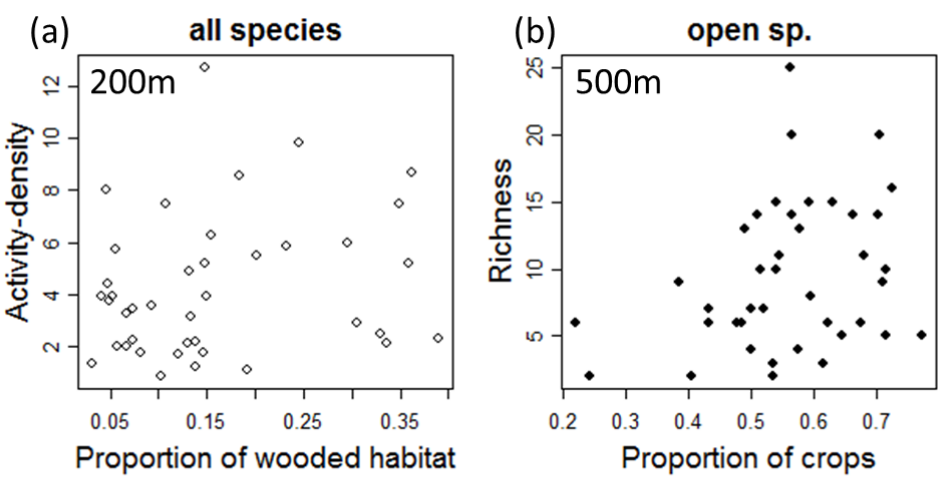

(c) forest sp.

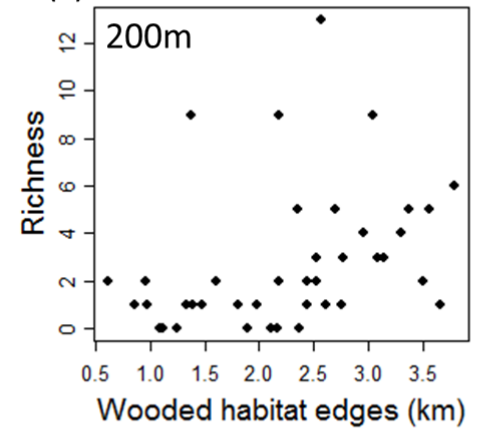

(d)

forest sp.

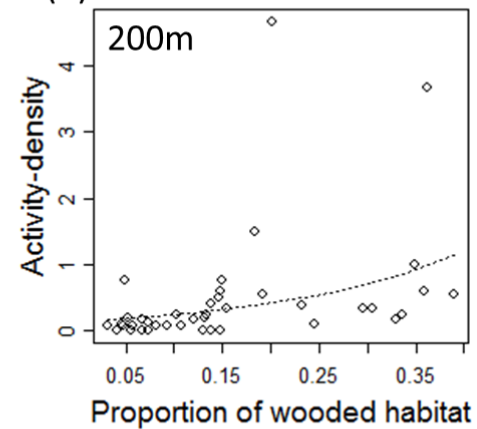

(e) apterous sp.

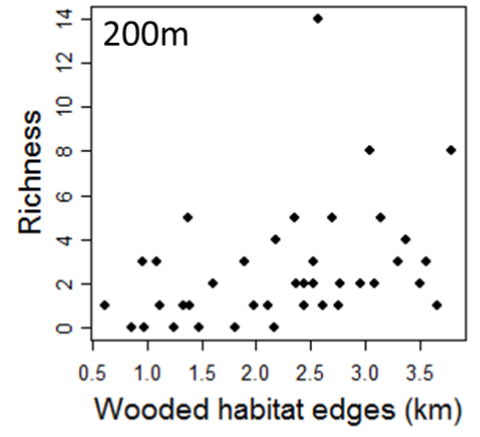

(f) apterous sp.

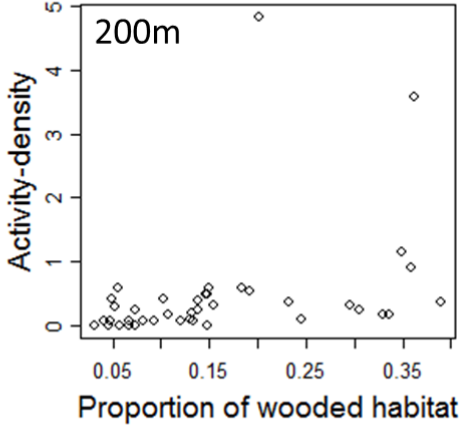

(g)

(h) macropterous sp.
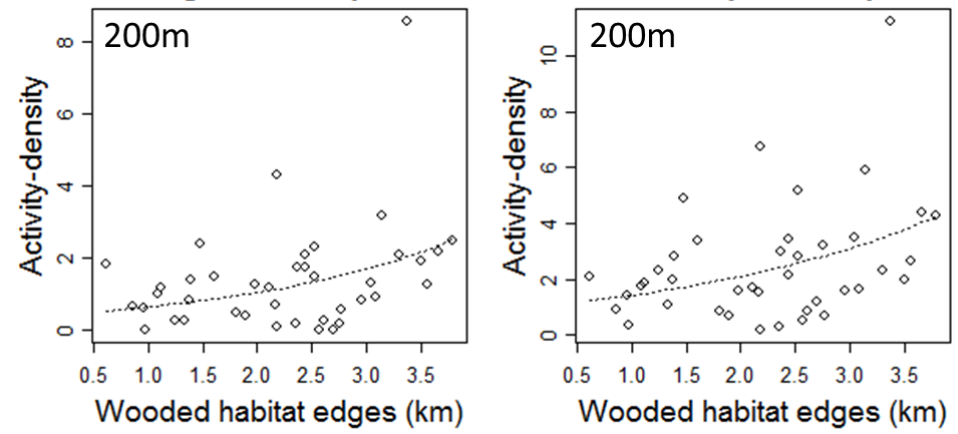

Figure 4. Graphical representation of significant and nearly significant results for carabid beetles biodiversity measures. Full dots are used for species richness, while empty dot and dashed lines are used for activity-density. Activity-density is expressed as number of individuals / valid trap / week. Scale of effects is indicated on each graph corner as the radius of buffers surrounding sampled permanent grasslands. Lines are given for illustrative purposes (only for significant results). Coefficients from average models are used for drawing linear and exponential lines (Appendix 1N). Exponential lines are used for Poisson and Negative Binomial distributions (log link functions). 
358 For birds, richness of breeding forest specialists increased with increasing length of wooded habitat 359 edges at the $200 \mathrm{~m}$ scale while their abundance was positively influenced by proportion of wooded 360 habitats also at the $200 \mathrm{~m}$ scale (Fig. 5b/c, Appendix 1O). As mentioned above, total richness of forest 361 specialist bird species was the only biodiversity measure to be influenced by a grassland landscape descriptor, i.e a nearly significant negative influence of large grassland patch area (Fig 5a, Appendix 10). Similarly, total richness and abundance of breeding generalist birds increased with increasing

364 length of wooded habitat edges at the 200m scale (Fig. 5d/e, Appendix 1O). Conversely, richness and 365 abundance of breeding farmland bird specialists decreased with increasing length of wooded habitat 366 edges, this time at the 500m scale (Fig. 5f/g, Appendix 1O). Birds with limited dispersal were not 367 affected by landscape descriptors, while medium and high dispersal groups responded significantly 368 (Appendix 1P) but this seems to have been more related to habitat affinity of the forest specialist or generalist species dominating these dispersal groups, than to dispersal ability per se, and so these results are not shown graphically. 
(a) forest sp.

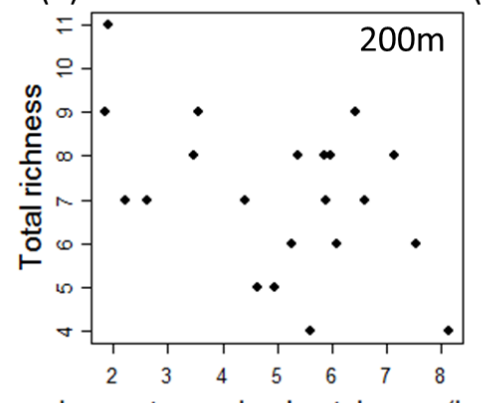

Largest grassland patch area (ha) (b)

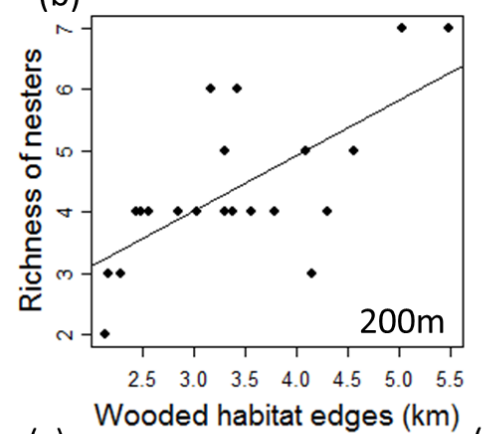

(c)

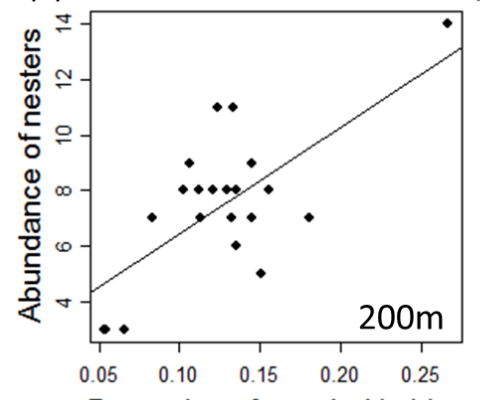

Proportion of wooded habitat (d)

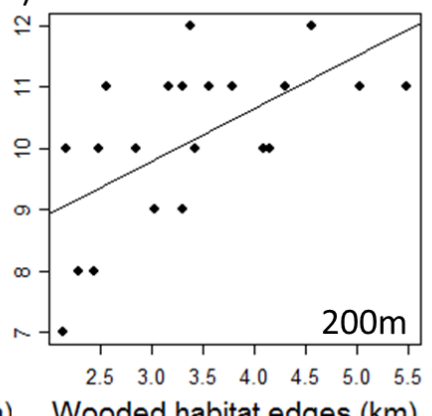

Wooded habitat edges (km)

\section{farmland sp.}

(f)

(e)

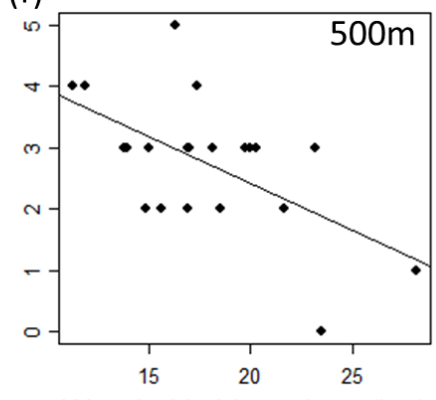

(g)

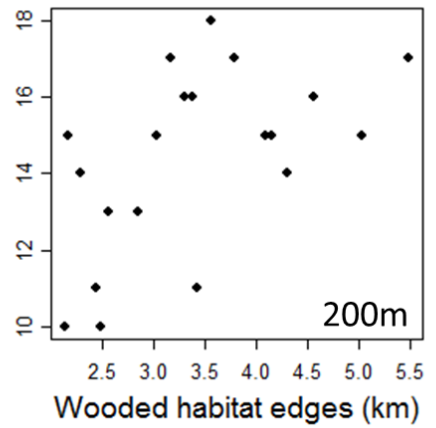

Figure 5. Graphical representation of significant and nearly significant results for bird habitat affinity groups. Scale of effects is indicated on each graph corner as the radius of buffers surrounding sampled permanent grasslands. Lines are given for illustrative purposes (only for significant results). Coefficients from average models are used for drawing linear (Appendix 1O), all models followed Gaussian distribution.

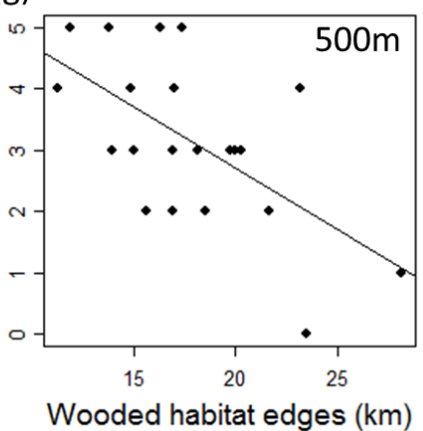


lack of response of these assemblages as a whole is perhaps not surprising. However, contrary to our hypothesis, even grassland specialist groups were unaffected. The lack of response of grassland assemblages to grassland amount was also noted by Soderstrom et al. (2001), who found no effect on either species richness or composition of plants, ground beetles and other insects (butterflies, bumble bees, dung beetles), and birds . However, in their study the proportion of grassland varied only from 0 to $17 \%$, while in this study it varied from at least 10 to $58 \%$ at the $200 \mathrm{~m}$ scale and 4 to $32 \%$ at the 500m scale, and despite this, there was still little response from the different groups. In our study, grassland connectivity index (sensu Hanski 1999) also varied (0-7) without significantly influencing the grassland assemblages. Similarly, Öckinger et al. (2012) found grassland isolation (inverse of Hanski index) had no effect on either total species richness of plants and insects (butterflies, bees or hoverflies), or on richness of grassland specialist groups. One could argue that if we had used a wider range of connectivity indices we might have found different effects. However Villemey et al. (2015) explored a much wider range of connectivity measures including Hanski index but also nearest Euclidean distance, graph-based measures with cost (least-cost path) or resistance (circuit theoretic) distances, only to come to the same conclusion for the butterfly assemblages they studied. The only group to respond to any measure of grassland connectivity was the total species richness of forest birds, which included 6 species not breeding in our study area, while the richness of breeding forest species alone did not. This suggests that certain species with a greater affinity for forest habitats may avoid very open areas, even when engaged in more temporary activities than breeding, such as dispersal or foraging. Configuration of grassland at 500m was sometimes selected by random forest procedures for plant assemblages. However, as for the other taxa, the effects of these descriptors were not significant.

Grassland specialists dominated plant assemblages, forming on average $83 \%$ of total species richness. Both grassland and total species richness were positively influenced by wooded habitats in the landscape as also shown by Soderstrom et al. (2001) and Ernoult et al. (2006). One hypothesis is that landscapes with more wooded habitats tend to be less disturbed and more species rich, and that wooded edges, particularly hedgerows, have well-developed herbaceous strata which may act as 
sources. Plant dispersal groups varied in their response to wooded habitats, independently from habitat affinity groups. Wind-dispersed species were unaffected by landscape context, in agreement with Piessens et al. (2005). However, we might have expected that wooded edges would inhibit flow of wind-dispersed seeds by forming physical barriers or reducing wind speed (Gaujour et al. 2012). Wooded habitat edges did promote animal-dispersed species, probably because seed-dispersing animals (birds, mammals, insects) tend themselves to follow woodland edges and hedgerows as they move.

In the case of carabids, the lack of grassland connectivity effects might be explained by the limited number of true grassland specialists (Roger et al. 2010; Neumann et al. 2016). Although grassland assemblages are clearly different from those observed in crop fields or wooded habitats (Duflot et al. 2015) some species considered to be crop or forest specialists are known to utilize permanent grasslands. Richness of open habitat carabid species tend to increase in landscapes with a greater proportion of crops, where a greater amount and diversity of complementary resources may be available (Duflot et al. 2016). Richness and activity-density of forest specialist species were higher in landscapes with more wooded habitat or edges (presence of hedgerows), which is a general observation for carabid assemblages found in farmland habitats (e.g. Millan-Pena et al. 2003; Aviron et al. 2005; Duflot et al. 2014). This is probably why total activity-density tended to increase with the proportion of wooded habitat in the landscape. Meanwhile, activity-density of generalist carabid species increased with increasing length of hedgerows, known to be overwintering sites for these species (Sotherton 1985; Thorbek and Bilde 2004). These results concur with studies in other contexts showing that carabid assemblages are strongly influenced by habitats adjacent to the focal habitat (Schneider et al. 2016; Yekwayo et al. 2016).

The majority of sampled birds were contacted in hedgerows delimiting each grassland or in trees or shrubs within, with relatively few observations of foraging in grasslands and $<1$ breeding territory per hectare within the grassland habitat itself (data not shown). Therefore, it is not surprising that landscape descriptors of wooded habitat amount and configuration best explained distributions of 
observed assemblages and more specifically of generalist and forest birds. Species more typical of open farmland habitats including grasslands are known to be negatively impacted by wooded or shrubby habitats in the landscape (Besnard et al. 2016) and we too found that wooded habitat edges reduced farmland bird richness and abundance of breeding farmland birds. Hedgerow avoidance behaviour of ground-nesting farmland birds is common and is partly due to increased predation risks associated with hedgerows and woodland edges (Besnard et al. 2016). The low dispersal ability group, which was composed of species with a diversity of habitat affinities, was not significantly affected by landscape context, although this group was expected to be the most sensitive to habitat connectivity. This study focused on breeding birds and we cannot rule out effects of landscape structure on this low dispersal group outside the breeding season and at wider geographical scales.

Given the composition of the sampled animal assemblages, it proved difficult to construct dispersal ability groups that would be independent from species habitat affinity and that would be comparable with other taxa. Although effects on plant dispersal groups were clearer, the positive, nearly significant, influence of wooded habitats on plant species dispersed by barochory was also difficult to explain. As Piessens et al. (2005) has highlighted, some plant species may disperse in a variety of ways making it difficult to define dispersal groups and to link dispersal processes with landscape structure.

Contrary to expectations, all three taxa responded mainly to landscape variables at the same $200 \mathrm{~m}$ scale. As the scale of landscape perception is expected to be between 4 to 9 times the average dispersal distance (Jackson and Fahrig 2012), the response of plant and carabids at the finer scale is less surprising than that of birds. It should be noted that most of the significant bird-landscape relationships related to breeding birds only, which are sedentary during the sampling season. Further investigation of a wider range of spatial scales of influence may yield different results. For both animal taxa, landscape configuration had opposite effects on open habitat and farmland species compared to forest and generalist species, and at different spatial scales. Farmland or open specialists seemed to have a wider scale of perception $(500 \mathrm{~m})$ than forest specialists and generalists $(200 \mathrm{~m})$, which suggests that 
response to landscape context was more dependent on habitat affinity than taxonomic group.

However, in the case of plants, ruderal species, more adapted to human disturbance and that included crop weeds, did not respond to increasing proportion of crops and/or decreased wooded habitats at the $500 \mathrm{~m}$ scale. Interestingly, for both animal groups richness of forest species of tended to increase with connectivity of wooded habitats (i.e. hedgerows), while their abundance or activity-density increased with resource availability (i.e. amount of wooded habitat).

\section{Conclusion}

We found no evidence that increasing connectivity of common, mesophilic, permanent grassland would have positive or indeed negative effects on plant and animal assemblages of such grassland habitats. Hence conservation planning to enhance the surface area and linkages between such grasslands within agricultural landscapes alone is unlikely to produce biodiversity increases, at least as far as our three study taxa are concerned. Instead, studied assemblages responded mostly to wooded habitats surrounding sampled grasslands, including hedgerows. Lengths of wooded habitat edges were often more important than the amount of wooded habitat itself, although collinearity between these landscape descriptors made it difficult to disentangle their independent effects. For grassland plant assemblages as a whole, or for the generalist or forest specialist components of the grassland animal assemblages, more woodland habitat in the landscape matrix is generally positive. Preserving or recreating landscapes composed of permanent grasslands interspersed with woodlands and hedgerows may be good policy, especially in regions where such forms of landscape organisation have been historically present and match with established and adapted biodiversity. Therefore, schemes aiming to reintroduce landscape complexity to farmland areas through hedge and tree planting should enhance biodiversity. However, the presence of open habitat carabids as well as farmland specialist birds depended on sufficiently large expanses of open land, free of wooded habitats. So, though increasing the area of common, permanent, mesophilic grassland did not influence these groups, maintaining sufficient areas of open land is crucial and potentially contradictory with the objectives of policies aiming to restore semi-natural, wooded habitats in farmland. These results illustrate the importance of 
497 approaches, to meet the needs of contrasting ecological groups.

\section{Acknowledgements}

500 We thank Frédéric Vaidie, Vincent Oury, Jean-Luc Roger and Marie Jagaille for assistance with field

501 and laboratory work. We are also grateful to Mathias Templin, Christian Hof, Matthias Schleuning,

502 Irina Nicholas, Katrin Böhning-Gaese for sharing bird measurements used to calculate the dispersal

503 ability predictor. This study was financed by the French Ministry for the Environment (DIVA 3:

504 public policy, agriculture \& biodiversity), the Conseil Régional des Pays de la Loire (URBIO:

505 Biodiversity of Urban Areas), and Angers Loire Métropole (post-doctoral grant). 


\section{References}

Allen VG, Batello C, Berretta EJ, et al (2011) An international terminology for grazing lands and grazing animals. Grass Forage Sci 66:2-28.

Arnold TW (2010) Uninformative parameters and model selection using Akaike's information criterion. J Wildl Manag 74:1175-1178.

Aviron S, Burel F, Baudry J, Schermann N (2005) Carabid assemblages in agricultural landscapes: impacts of habitat features, landscape context at different spatial scales and farming intensity. Agric Ecosyst Environ 108:205-217.

Aviron S, Poggi S, Varennes Y-D, Lefèvre A (2016). Local landscape heterogeneity affects crop colonization by natural enemies in protected horticultural cropping systems Agric Ecosyst Environ 227:1-10.

Barbaro L, van Halder I (2009) Linking bird, carabid beetle and butterfly life-history traits to habitat fragmentation in mosaic landscapes. Ecography 32:321-333.

Barton K (2016) MuMIn: Multi-Model Inference.

Bates D, Mächler M, Bolker B, Walker S (2015) Fitting Linear Mixed-Effects Models Using Ime4. J Stat Softw 67:1-48. doi: 10.18637/jss.v067.i01

Bennett AF (2003) Linkages in th Landscape: The Role of Corridors and Connectivity in Wildlife Conservation. IUCN, Gland, Switzerland and Cambridge, UK

Bennett AF, Saunders DA (2010) Habitat fragmentation and landscape change. In: Conservation biology for All, Oxford University Press. Navjot S. Sodhi and Paul R. Ehrlich, Oxford, UK, pp 1544-1550

Benton TG, Vickery J, Wilson J (2003) Farmland biodiversity: is habitat heterogeneity the key? Trends Ecol Evol 18:182-188.

Besnard AG, Fourcade Y, Secondi J (2016) Measuring difference in edge avoidance in grassland birds: the Corncrake is less sensitive to hedgerow proximity than passerines. J Ornithol 157:515523. doi: 10.1007/s10336-015-1281-7

BETSI, 2012. A database for biological and ecological functional traits of soil invertebrates. French foundation for biodiversity research.

Bjornstad ON (2016) ncf: Spatial Nonparametric Covariance Functions.

Boitani L, Falcucci A, Maiorano L, Rondinini C (2007) Ecological networks as conceptual frameworks or operational tools in conservation. Conserv Biol 21:1414-1422. doi: 10.1111/j.15231739.2007.00828.x

Bouche G, Lepage B, Migeot V, Ingrand P (2009) Application of detecting and taking overdispersion into account in Poisson regression model. Rev Dépidemiologie Sante Publique 57:285-296.

Boussard H, Baudry J (2014) Chloe2012 : a software for landscape pattern analysis, http://www.rennes.inra.fr/sad/Outils-Produits/Outils-informatiques/Chloe. 
Brückmann SV, Krauss J, Steffan-Dewenter I (2010) Butterfly and plant specialists suffer from reduced connectivity in fragmented landscapes. J Appl Ecol 47:799-809. doi: 10.1111/j.13652664.2010.01828.x

Burnham KP, Anderson DR (2002) Model selection and Multi-Model Inference. A practical information-theoretic Approach, 2nd Ed. Springer-Verlag, New York, USA

Chamberlain D, Fuller R, Bunce R, et al (2000) Changes in the abundance of farmland birds in relation to the timing of agricultural intensification in England and Wales. J Appl Ecol 37:771-788. doi: 10.1046/j.1365-2664.2000.00548.x

Chao A (1987). Estimating the population size for capture-recapture data with unequal catchability. Biometrics 43:783-791

Crawley MJ (2007) The R Book. John Wiley \& Sons, New York, USA

Crooks KR, Sanjayan M (2006) Connectivity Conservation. Cambridge University Press, New York, USA

Davies ZG, Pullin AS (2007) Are hedgerows effective corridors between fragments of woodland habitat? An evidence-based approach. Landsc Ecol 22:333-351. doi: 10.1007/s10980-0069064-4

Dawideit BA, Phillimore AB, Laube I, et al (2009) Ecomorphological predictors of natal dispersal distances in birds. J Anim Ecol 78:388-395. doi: 10.1111/j.1365-2656.2008.01504.x

Donald PF, Green RE, Heath MF (2001) Agricultural intensification and the collapse of Europe's farmland bird populations. Proc R Soc Lond B 268:25-29.

Duflot R, Ernoult A, Burel F, Aviron S (2016) Landscape level processes driving carabid crop assemblage in dynamic farmlands. Popul Ecol 58:265-275. doi: 10.1007/s10144-015-0534-x

Duflot R, Georges R, Ernoult A, et al (2014) Landscape heterogeneity as an ecological filter of species traits. Acta Oecologica 56:19-26.

Ernoult A, Tremauville Y, Cellier D, et al (2006) Potential landscape drivers of biodiversity components in a flood plain: Past or present patterns? Biol Conserv 127:1-17.

Faïq C, Fuzeau V, Cahuzac E, et al (2013) Les prairies permanentes : Evolution des surfaces en France - Analyse à travers le Registre Parcellaire Graphique, Commissariat Général au Développement Durable. Ed Bonnet X.

Filippi-Codaccioni O, Devictor V, Bas Y, Julliard R (2010) Toward more concern for specialisation and less for species diversity in conserving farmland biodiversity. Biol Conserv 143:1493-1500.

Foley JA, DeFries R, Asner GP, et al (2005) Global consequences of land use. Science 309:570-574.

Gaston KJ (2008) Biodiversity and extinction: the importance of being common. Prog Phys Geogr 32:73-79. doi: 10.1177/0309133308089499

Gaston KJ, Fuller RA (2008) Commonness, population depletion and conservation biology. TRENDS Ecol Evol 23:14-19. doi: 10.1016/j.tree.2007.11.001 
Gaujour E, Amiaud B, Mignolet C, Plantureux S (2012) Factors and processes affecting plant biodiversity in permanent grasslands. A review. Agron Sustain Dev 32:133-160.

Gelling M, Macdonald DW, Mathews F (2007) Are hedgerows the route to increased farmland small mammal density? Use of hedgerows in British pastoral habitats. Landsc Ecol 22:1019-1032. doi: 10.1007/s10980-007-9088-4

Gil-Tena A, Nabucet J, Mony C, et al (2014) Woodland bird response to landscape connectivity in an agriculture-dominated landscape: a functional community approach.

Hanski I (1999) Habitat Connectivity, Habitat Continuity, and Metapopulations in Dynamic Landscapes. Oikos 87:209-219. doi: 10.2307/3546736

Hendrickx F, Maelfait JP, Van Wingerden W, et al (2007) How landscape structure, land-use intensity and habitat diversity affect components of total arthropod diversity in agricultural landscapes. J Appl Ecol 44:340-351.

Hothorn T, Hornik K, Strobl C, Zeileis A (2013) party : A Laboratory for Recursive Partytioning.

Inger R, Gregory R, Duffy JP, et al (2015) Common European birds are declining rapidly while less abundant species' numbers are rising. Ecol Lett 18:28-36. doi: 10.1111/ele.12387

Irmler U, Hoernes U (2003) Assignment and evaluation of ground beetle (Coleoptera: Carabidae) assemblages to sites on different scales in a grassland landscape. Biodiversity and Conservation 12: 1405-1419

Jackson HB, Fahrig L (2012) What size is a biologically relevant landscape? Landsc Ecol 27:929-941. doi: 10.1007/s10980-012-9757-9

Jamoneau A, Sonnier G, Chabrerie O, et al (2011) Drivers of plant species assemblages in forest patches among contrasted dynamic agricultural landscapes. J Ecol 99:1152-1161.

Jiguet F (2010) Les résultats nationaux du programme STOC de 1989 à 2010.

Jongman RHG, Bouwma IM, Griffioen A, et al (2011) The Pan European Ecological Network: PEEN. Landsc Ecol 26:311-326. doi: 10.1007/s10980-010-9567-x

Julve P (1998) BaseVeg. Répertoire synonymique des groupements végétaux de France.

Kotze DJ, O'Hara RB (2003) Species decline - but why? Explanations of carabid beetle (Coleoptera, Carabidae) declines in Europe. Oecologia 135:138-148.

Kuhn I, Durka W, Klotz S (2004) BiolFlor - a new plant-trait database as a tool for plant invasion ecology. Divers Distrib 10:363-365.

Lafage D, Maugenest S, Bouzillé J-B, Pétillon J (2015) Disentangling the influence of local and landscape factors on alpha and beta diversities: opposite response of plants and grounddwelling arthropods in wet meadows. Ecol Res 30:1025-1035. doi: 10.1007/s11284-0151304-0

Laube I, Korntheuer H, Schwager M, et al (2013) Towards a more mechanistic understanding of traits and range sizes. Glob Ecol Biogeogr 22:233-241. doi: 10.1111/j.1466-8238.2012.00798.x 
Liira J, Schmidt T, Aavik T, et al (2008) Plant functional group composition and large-scale species richness in European agricultural landscapes. J Veg Sci 19:3-14.

Marchadour B (2014) Oiseaux nicheurs des Pays de la Loire. Coordination régionale LPO Pays de la Loire, Delachaux et Niestlé, Paris, France

Marini L, Fontana P, Scotton M, Klimek S (2008) Vascular plant and Orthoptera diversity in relation to grassland management and landscape composition in the European Alps. J Appl Ecol 45:361370.

Mauremooto JR, Wratten SD, Worner SP, Fry GLA (1995) Permeability of Hedgerows to Predatory Carabid Beetles. Agric Ecosyst Environ 52:141-148.

Meeus JHA (1993) The transformation of agricultural landscapes in Western-Europe. Sci Total Environ 129:171-190.

Millan-Pena N, Butet A, Delettre Y, et al (2003) Landscape context and carabid beetles (Coleoptera : Carabidae) communities of hedgerows in western France. Agric Ecosyst Environ 94:59-72.

Neumann JL, Griffiths GH, Hoodless A, Holloway GJ (2016) The compositional and configurational heterogeneity of matrix habitats shape woodland carabid communities in woodedagricultural landscapes. Landsc Ecol 31:301-315. doi: 10.1007/s10980-015-0244-y

Öckinger E, Lindborg R, Sjödin NE, Bommarco R (2012) Landscape matrix modifies richness of plants and insects in grassland fragments. Ecography 35:259-267. doi: 10.1111/j.16000587.2011.06870.x

Oksanen J, Blanchet FG, Kindt R, Legendre P, Minchin PR, O'Hara RB, Simpson GL, Solymos P, Henry $M$, Stevens $H$, Wagner $H$ (2013) Vegan: community ecology package.

Petit S (1994) Diffusion of forest carabid species in hedgerow network landscapes. In: K. Desender MLL et J-PM M Dufrêne, M Loreau (ed) Carabid beetles: ecology and evolution. Kluwer Academic Publisher, Netherlands, pp 337-443

Piessens K, Honnay O, Hermy M (2005) The role of fragment area and isolation in the conservation of heathland species. Biol Conserv 122:61-69. doi: 10.1016/j.biocon.2004.05.023

Puech C, Baudry J, Joannon A, et al (2014) Organic vs. conventional farming dichotomy: Does it make sense for natural enemies? Agric Ecosyst Environ 194:48-57. doi: http://doi.org/10.1016/j.agee.2014.05.002

Purtauf T, Dauber J, Wolters V (2004) Carabid communities in the spatio-temporal mosaic of a rural landscape. Landsc Urban Plan 67:185-193.

QGIS Development Team, 2015. QGIS geographic information system. Open Source Geospatial Foundation. https://www.qgis.org

R Core Team (2016) R: A Language and Environment for Statistical Computing. R Foundation for Statistical Computing, Vienna, Austria

Ribera I, Doledec S, Downie IS, Foster GN (2001) Effect of land disturbance and stress on species traits of ground beetle assemblages. Ecology 82:1112-1129. 
Robinson RA, Sutherland WJ (2002) Post-war changes in arable farming and biodiversity in Great Britain. J Appl Ecol 39:157-176.

Roger J-L, Jambon O, Bouger G (2010) Clé de détermination des carabidés : Paysages agricoles de la Zone Atelier d'Armorique. Laboratoires INRA SAD-Paysage et CNRS ECOBIO, Rennes, France

Rösch V, Tscharntke T, Scherber C, Batáry P (2013) Landscape composition, connectivity and fragment size drive effects of grassland fragmentation on insect communities. J Appl Ecol 50:387-394. doi: 10.1111/1365-2664.12056

Samways MJ, Pryke JS (2016) Large-scale ecological networks do work in an ecologically complex biodiversity hotspot. Ambio 2016, 45: 161-172 doi: 10.1007/s13280-015-0697-x

Scrucca L (2004) qcc: an R package for quality control charting and statistical process control. R News 4/1:11-17.

Schneider G, Krauss J, Boetzl FA, Fritze MA, Steffan-Dewenter I (2016) Spillover from adjacent crop and forest habitats shapes carabid beetle assemblages in fragmented semi natural grasslands. Oecologia 182 (4): 1141-1150 doi: 10.1007/s00442-016-3710-6Smith AC, Fahrig L, Francis CM (2011) Landscape size affects the relative importance of habitat amount, habitat fragmentation, and matrix quality on forest birds. Ecography 34:103-113.

Smith AC, Koper N, Francis CM, Fahrig L (2009) Confronting collinearity: comparing methods for disentangling the effects of habitat loss and fragmentation. Landsc Ecol 24:1271-1285.

Soderstrom B, Svensson B, Vessby K, Glimskar A (2001) Plants, insects and birds in semi-natural pastures in relation to local habitat and landscape factors. Biodivers Conserv 10:1839-1863.

Sotherton NW (1985) The distribution and abundance of predatory coleoptera overwintering in field boundaries. Ann Appl Biol 106:17-21.

Steffan-Dewenter I (2003) Importance of Habitat Area and Landscape Context for Species Richness of Bees and Wasps in Fragmented Orchard Meadows. Conserv Biol 17:1036-1044. doi: 10.1046/j.1523-1739.2003.01575.x

Strobl C, Boulesteix A-L, Kneib T, et al (2008) Conditional variable importance for random forests. BMC Bioinformatics 9:307. doi: 10.1186/1471-2105-9-307

Strobl C, Malley J, Tutz G (2009) An Introduction to Recursive Partitioning: Rationale, Application and Characteristics of Classification and Regression Trees, Bagging and Random Forests. Psychol Methods 14:323-348. doi: 10.1037/a0016973

Thomas CFG, Parkinson L, Marshall EJP (1998) Isolating the components of activity-density for the carabid beetle Pterostichus melanarius in farmland. Oecologia 116:103-112.

Thorbek P, Bilde T (2004) Reduced numbers of generalist arthropod predators after crop management. J Appl Ecol 41:526-538.

Tscharntke T, Tylianakis JM, Rand TA, et al (2012) Landscape moderation of biodiversity patterns and processes - eight hypotheses. Biol Rev 87:661-685. 
Vanpeene-Bruhier S., Amsallem J., 2014. Schémas régionaux de cohérence écologique : les questionnements, les méthodes d'identification utilisées, les lacunes. Sciences Eaux \& Territoires 14, 2-5

Villemey A, Halder I van, Ouin A, et al (2015) Mosaic of grasslands and woodlands is more effective than habitat connectivity to conserve butterflies in French farmland. Biol Conserv 191:206215. doi: http://doi.org/10.1016/j.biocon.2015.06.030

Wamser S, Diekotter T, Boldt L, et al (2012) Trait-specific effects of habitat isolation on carabid species richness and community composition in managed grasslands. Insect Conserv Divers 5:9-18.

Yekwayo I, Pryke JS, Roets F, Samways MJ (2016) Surrounding vegetation matters for arthropods of small, natural patches of indigenous forest. Insect Conserv Divers 9: 224-235. doi:10.1111/icad.12160 


\section{Online appendixes 1}

\section{Appendix 1A}

Map of the study areas. (a) Geographical location of the study region in France. (b) Geographical location of the four study areas in north-western France. In brackets, the number of sampled grasslands in each study area (LSRY = La Roche-sur-Yon).

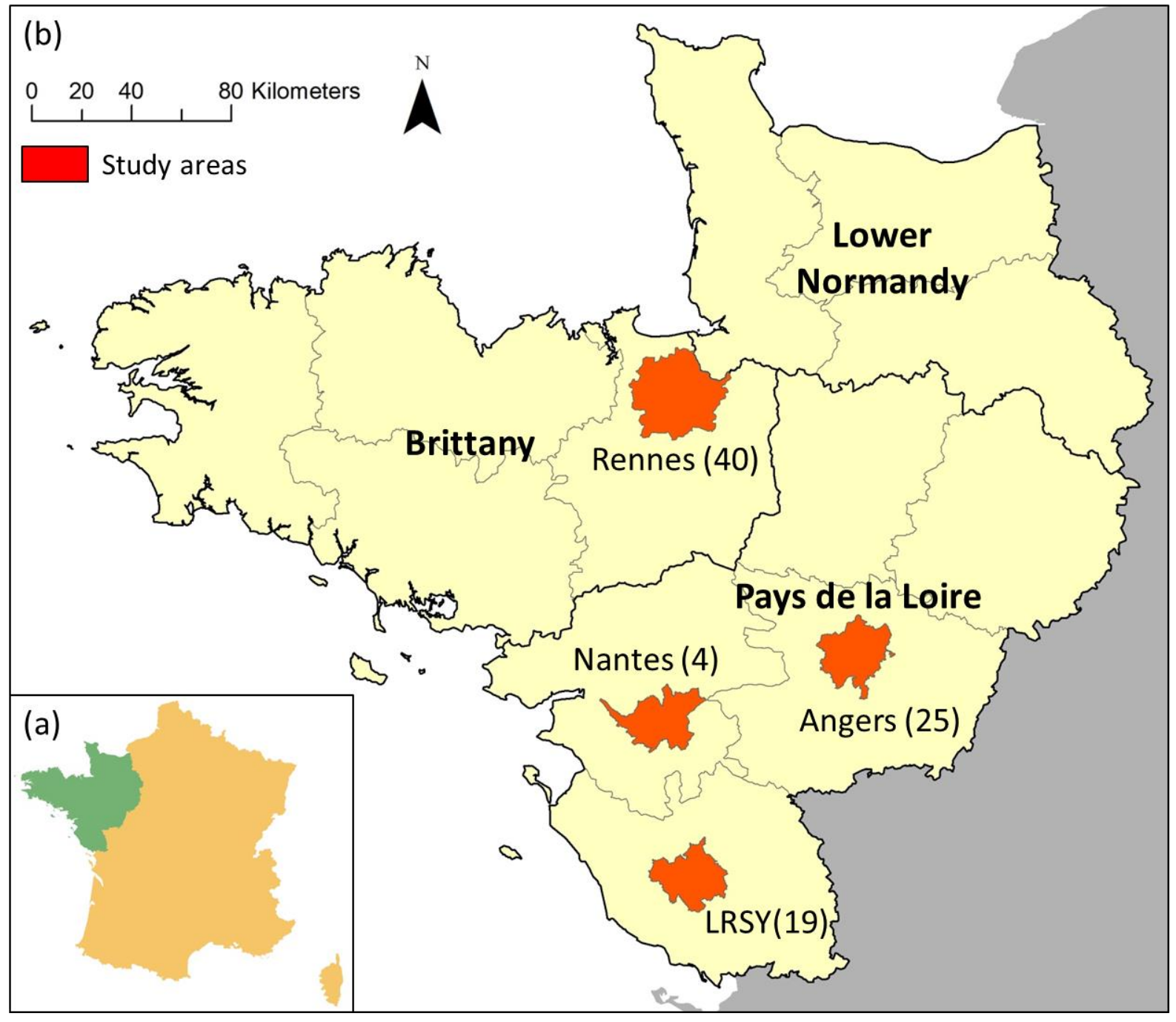




\section{Appendix 1B}

Distribution of plant species among the different biological groups within the sampled permanent grasslands. Species occurrence is the number of species observations across all sampled permanent grasslands (maximum occurrence $=55$ ). Anemochorous: winddispersed, barochorous gravity-dispersed, zoochorous: animal-dispersed. NA: species for which data were not available, others: autochorous and hydrochorous.

Species number

\begin{tabular}{lccccc}
\hline & anemochorous & barochorous & zoochorous & NA / others & Total \\
\hline forest & 3 & 4 & 6 & 1 & $\mathbf{1 4}$ \\
grassland & 10 & 25 & 23 & 1 & $\mathbf{5 9}$ \\
ruderal & 5 & 8 & 12 & 1 & $\mathbf{2 6}$ \\
NA & & 1 & 2 & 6 & $\mathbf{9}$ \\
\hline Total & $\mathbf{1 8}$ & $\mathbf{3 8}$ & $\mathbf{4 3}$ & $\mathbf{9}$ & $\mathbf{1 0 8}$ \\
\hline
\end{tabular}

Summed species occurrences

\begin{tabular}{lccccc}
\hline & anemochorous & barochorous & zoochorous & NA / others & Total \\
\hline forest & 6 & 11 & 21 & 1 & 39 \\
grassland & 131 & 243 & 296 & 2 & $\mathbf{6 7 2}$ \\
ruderal & 17 & 49 & 37 & 1 & $\mathbf{1 0 4}$ \\
NA & & 1 & 2 & 7 & 10 \\
\hline Total & $\mathbf{1 5 4}$ & $\mathbf{3 0 4}$ & $\mathbf{3 5 6}$ & $\mathbf{1 1}$ & $\mathbf{8 2 5}$ \\
\hline
\end{tabular}




\section{Appendix 1C}

Distribution of carabid beetle species among the different biological groups within the sampled permanent grasslands. Species occurrence is the number of species observations across all sampled permanent grasslands (maximum occurrence $=40$ ). Apterous: windless, dimorphic: undeveloped wings, macropterous: winged. Activity-density is expressed as number of individuals / valid trap / week. NA: species for which data were not available.

\begin{tabular}{lccccc}
\multicolumn{2}{l}{ Species number } & \multicolumn{5}{l}{} \\
\hline & apterous & dimorphic & macropterous & NA & Total \\
\hline crop & 2 & 2 & 11 & & $\mathbf{1 5}$ \\
forest & 8 & 6 & 1 & $\mathbf{1 5}$ \\
generalist & 1 & 1 & 5 & & $\mathbf{7}$ \\
open habitat & & 7 & 11 & & $\mathbf{1 8}$ \\
NA & 3 & 3 & 14 & 1 & $\mathbf{2 1}$ \\
\hline Total & $\mathbf{1 4}$ & $\mathbf{1 9}$ & $\mathbf{4 2}$ & $\mathbf{1}$ & $\mathbf{7 6}$ \\
\hline
\end{tabular}

Summed species occurrences

\begin{tabular}{lccccc}
\hline & apterous & dimorphic & macropterous & NA & Total \\
\hline crop & 7 & 15 & 92 & & $\mathbf{1 1 4}$ \\
forest & 79 & 29 & 3 & 152 & $\mathbf{1 1 1}$ \\
generalist & 14 & 1 & 194 & & $\mathbf{1 6 7}$ \\
open & & 184 & 34 & 3 & $\mathbf{3 7 8}$ \\
NA & 6 & 7 & $\mathbf{4 7 5}$ & $\mathbf{3}$ & $\mathbf{8 2 0}$ \\
\hline Total & $\mathbf{1 0 6}$ & $\mathbf{2 3 6}$ & & & \\
\hline
\end{tabular}

Summed activity-density

\begin{tabular}{lccccc}
\hline & apterous & dimorphic & macropterous & NA & Total \\
\hline crop & 0.70 & 1.62 & 15.20 & & $\mathbf{1 7 . 5 1}$ \\
forest & 15.84 & 3.26 & 0.25 & & $\mathbf{1 9 . 3 5}$ \\
generalist & 1.82 & 0.10 & 53.86 & & $\mathbf{5 5 . 7 7}$ \\
open habitat & & 44.96 & 27.90 & & $\mathbf{7 2 . 8 6}$ \\
NA & 0.61 & 0.63 & 3.65 & 0.27 & $\mathbf{5 . 1 6}$ \\
\hline Total & $\mathbf{1 8 . 9 6}$ & $\mathbf{5 0 . 5 7}$ & $\mathbf{1 0 0 . 8 6}$ & $\mathbf{0 . 2 7}$ & $\mathbf{1 7 0 . 6 6}$ \\
\hline
\end{tabular}




\section{Appendix 1D}

Distribution of bird species among the different biological groups within the sampled permanent grasslands, for total species pool and nesters. Species occurrence is the number of species observations across all sampled permanent grasslands (maximum occurrence = 21). Dispersal ability groups were obtained by splitting a dispersal ability predictor into categories using natural breaks (Jenks). NA: species for which data were not available. * unstudied biological groups.

Species number

\begin{tabular}{lcccccc}
\hline & low & medium & high & long distance* & NA & Total \\
\hline farmland & 2 & 4 & 6 & 2 & 3 & $\mathbf{1 7}$ \\
forest & 5 & 8 & 6 & & & $\mathbf{1 9}$ \\
generalist & 6 & 4 & 6 & 2 & 2 & $\mathbf{2 0}$ \\
urban* & 3 & 1 & 5 & 2 & & $\mathbf{1 1}$ \\
NA & & & & & 5 & $\mathbf{5}$ \\
\hline Total & $\mathbf{1 6}$ & $\mathbf{1 7}$ & $\mathbf{2 3}$ & $\mathbf{6}$ & $\mathbf{1 0}$ & $\mathbf{7 2}$ \\
\hline
\end{tabular}

Summed species occurrences

\begin{tabular}{lcccccc}
\hline & low & medium & high & long distance* & NA & Total \\
\hline farmland & 23 & 40 & 21 & 23 & 9 & $\mathbf{1 1 6}$ \\
forest & 29 & 90 & 61 & & & $\mathbf{1 8 0}$ \\
generalist & 112 & 78 & 35 & 33 & 2 & $\mathbf{2 6 0}$ \\
urban* & 23 & 7 & 22 & 16 & & $\mathbf{6 8}$ \\
NA & & & & & 7 & $\mathbf{7}$ \\
\hline Total & $\mathbf{1 8 7}$ & $\mathbf{2 1 5}$ & $\mathbf{1 3 9}$ & $\mathbf{7 2}$ & $\mathbf{1 8}$ & $\mathbf{6 3 1}$ \\
\hline
\end{tabular}

Nesting species number

\begin{tabular}{lcccccc}
\hline & low & medium & high & long distance* & NA & Total \\
\hline farmland & 2 & 4 & 3 & 2 & 1 & $\mathbf{1 2}$ \\
forest & 1 & 7 & 5 & & & $\mathbf{1 3}$ \\
generalist & 5 & 4 & 4 & 2 & & $\mathbf{1 5}$ \\
urban* & 3 & 1 & 2 & & 1 & $\mathbf{6}$ \\
NA & & & & & $\mathbf{2}$ & $\mathbf{4 7}$ \\
\hline Total & $\mathbf{1 1}$ & $\mathbf{1 6}$ & $\mathbf{1 4}$ & $\mathbf{4}$ & $\mathbf{2}$
\end{tabular}

Summed nesting species occurrences

\begin{tabular}{lcccccc}
\hline & low & medium & high & long distance* & NA & Total \\
\hline farmland & 21 & 29 & 9 & 8 & 1 & $\mathbf{6 8}$ \\
forest & 24 & 65 & 25 & & & $\mathbf{1 1 4}$ \\
generalist & 98 & 66 & 25 & 18 & & $\mathbf{2 0 7}$ \\
urban* & 13 & 4 & 7 & & & $\mathbf{2 4}$ \\
NA & & & & & 1 & $\mathbf{1}$ \\
\hline Total & $\mathbf{1 5 6}$ & $\mathbf{1 6 4}$ & $\mathbf{6 6}$ & $\mathbf{2 6}$ & $\mathbf{2}$ & $\mathbf{4 1 4}$ \\
\hline
\end{tabular}

Nesting species summed abundance

\begin{tabular}{|c|c|c|c|c|c|c|}
\hline & low & medium & high & long distance* & NA & Total \\
\hline farmland & 23 & 35 & 9 & 8 & 1 & 76 \\
\hline forest & 42 & 126 & 30 & & & 198 \\
\hline generalist & 182 & 131 & 37 & 21 & & 371 \\
\hline urban* & 15 & 4 & 7 & & & 26 \\
\hline NA & & & & & 1 & 1 \\
\hline Total & 262 & 296 & 83 & 29 & 2 & 672 \\
\hline
\end{tabular}




\section{Appendix 1E}

Range of values of studied landscape descriptors, in a 200m-radius buffer surrounding sampled permanent grasslands, for each taxon. Each dot represents a landscape. Proportions are expressed as percentage.

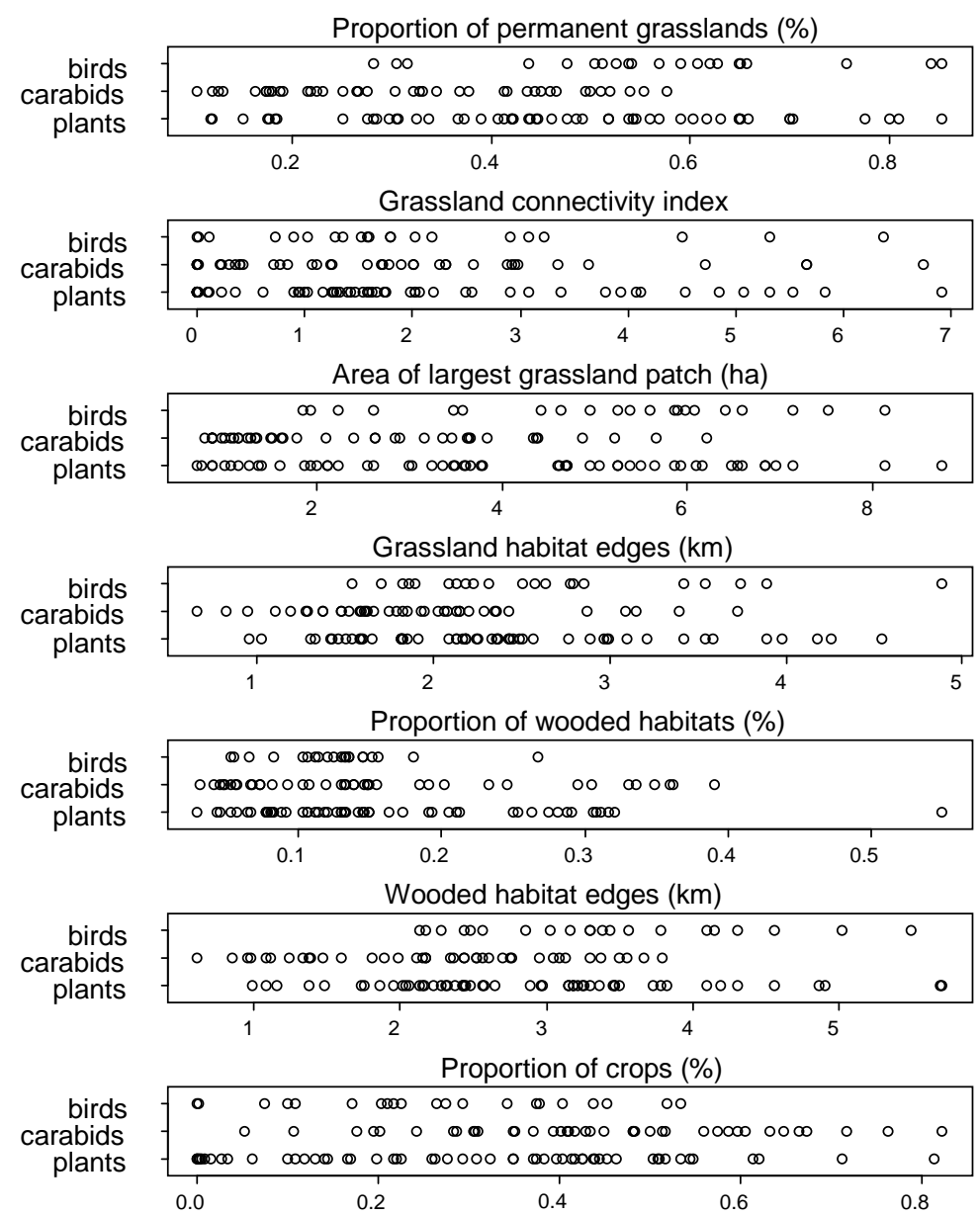




\section{Appendix 1F}

Range of values of studied landscape descriptors, in a $500 \mathrm{~m}$-radius buffer surrounding sampled permanent grasslands for each taxon. Each dot represents a landscape. Proportions are expressed as percentage.

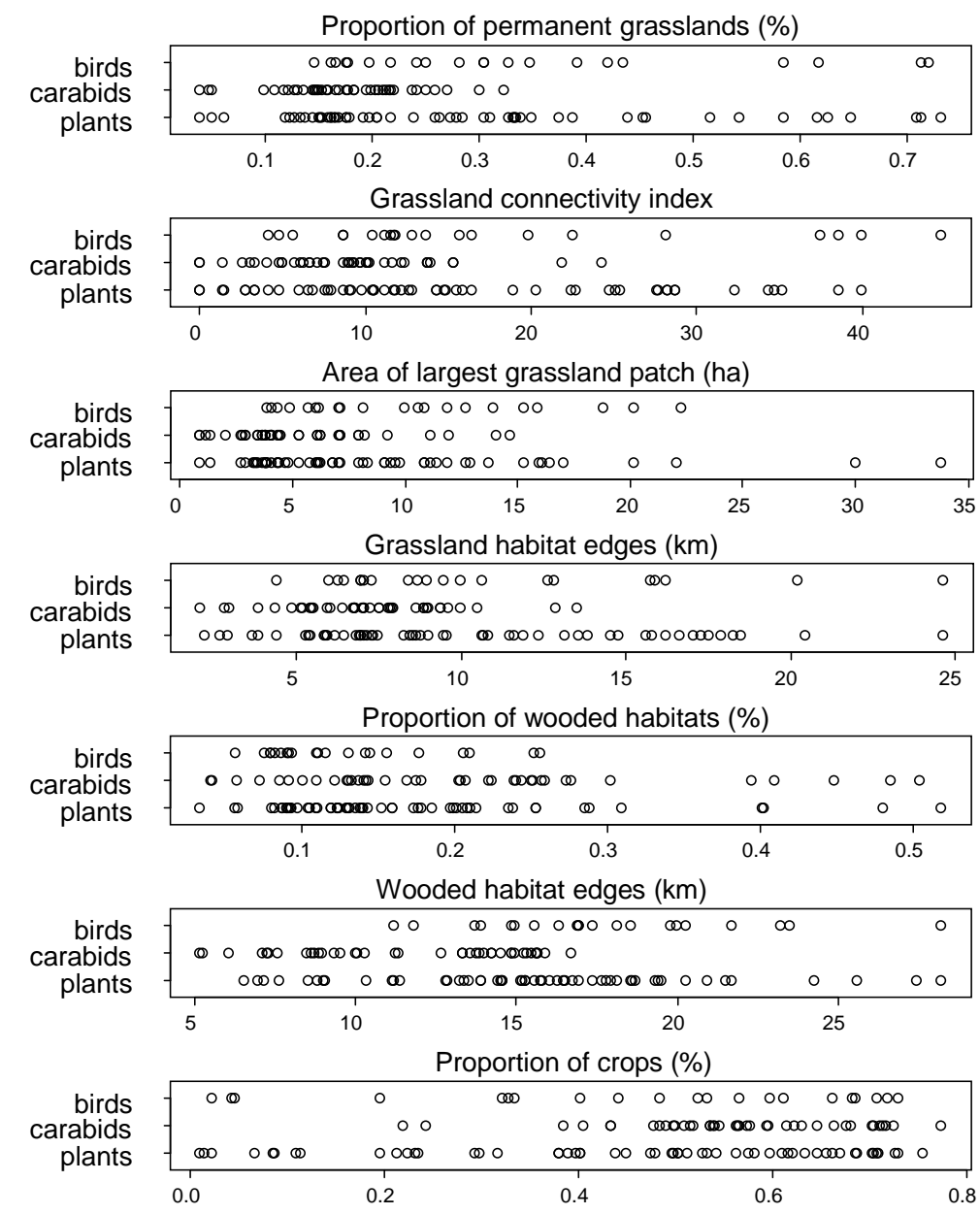




\section{Appendix 1G}

Pearson correlation coefficient for all pairs of landscape descriptors measured for plantsampled permanent grasslands $(n=55)$. Highest correlation coefficients $(>|0.7|)$ are indicated in bold characters. \% PG: proportion of permanent grassland (\%), PG connect: permanent grassland connectivity index, PG LP: largest permanent grassland patch (ha), PG edges: permanent grassland edges $(\mathrm{km}), \% \mathrm{WH}$ : proportion of wooded habitat (\%), WH edges: wooded habitat edges $(\mathrm{km}), \%$ crops: proportion of crop (\%)

$200 \mathrm{~m}$

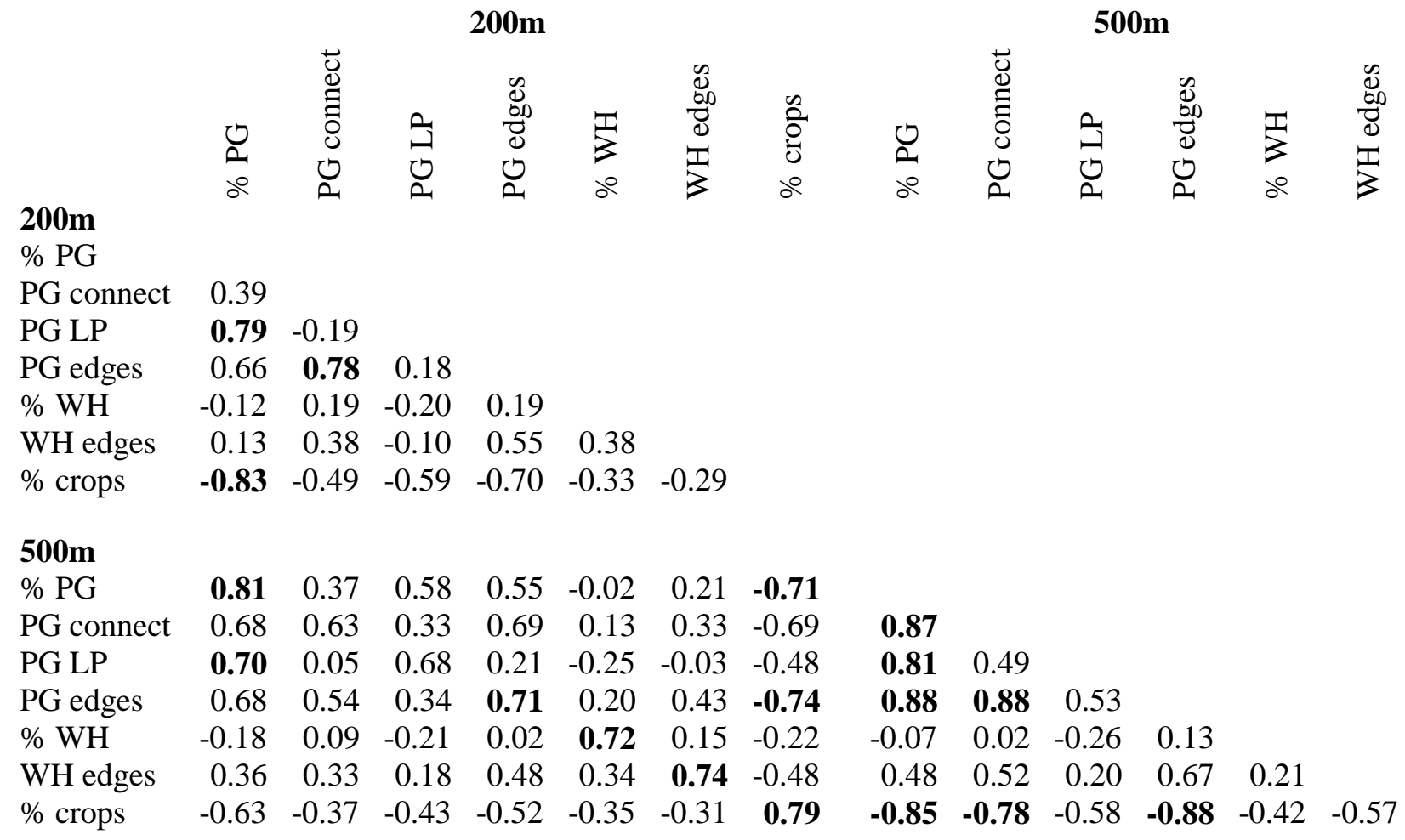




\section{Appendix 1H}

Pearson correlation coefficient for all pairs of landscape descriptors measured for carabidsampled permanent grasslands. $(n=40)$ Highest correlation coefficients $(>|0.7|)$ are indicated in bold. \% PG: proportion of permanent grassland (\%), PG connect: permanent grassland connectivity index, PG LP: largest permanent grassland patch (ha), PG edges: permanent grassland edges $(\mathrm{km}), \% \mathrm{WH}$ : proportion of wooded habitat (\%), WH edges: wooded habitat edges $(\mathrm{km}), \%$ crops: proportion of crop (\%)

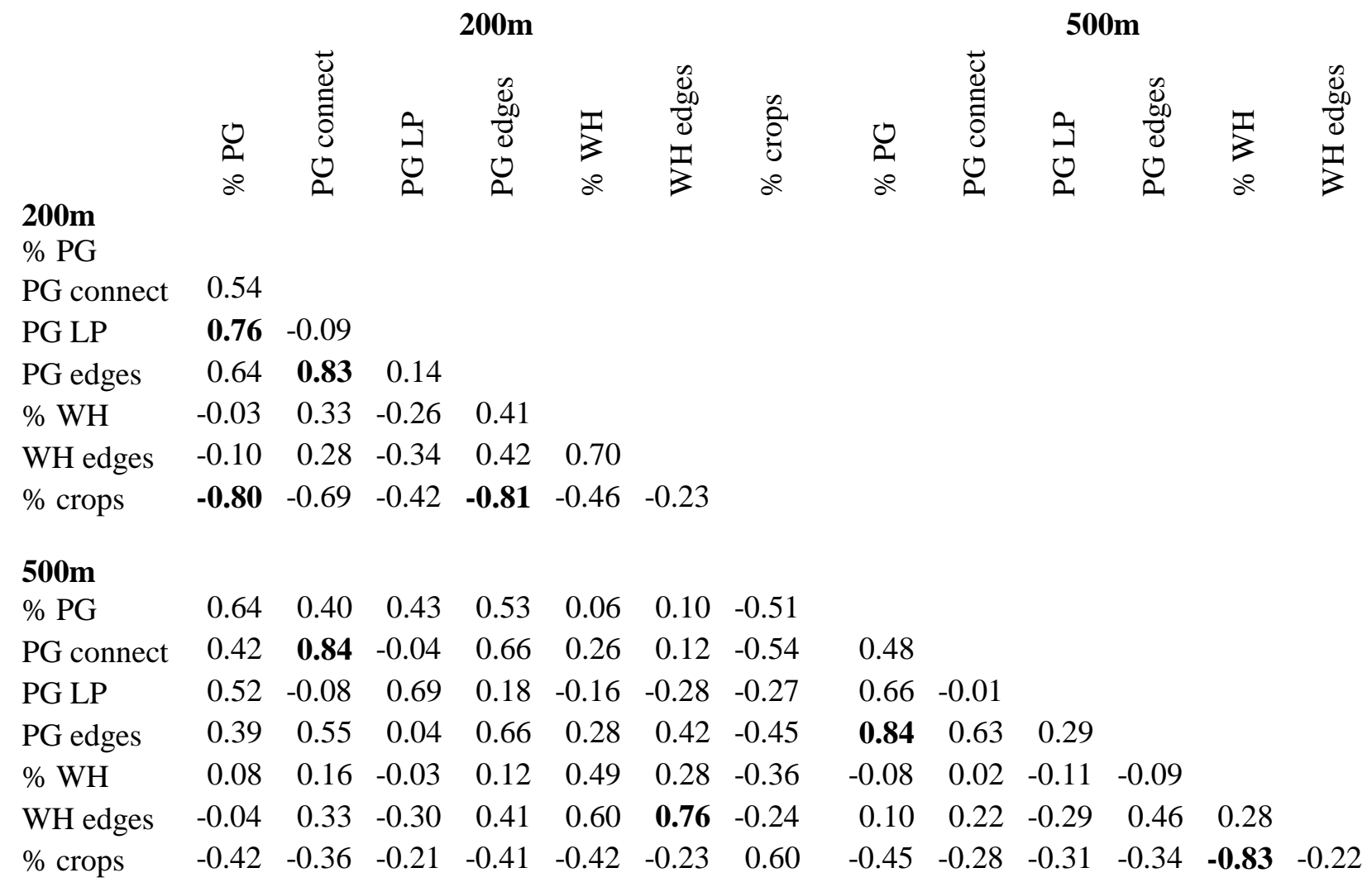




\section{Appendix 1I}

Pearson correlation coefficient for all pairs of landscape descriptors measured for birdsampled permanent grasslands $(n=21)$. Highest correlation coefficients $(>|0.7|)$ are indicated in bold characters. \% PG: proportion of permanent grassland (\%), PG connect: permanent grassland connectivity index, PG LP: largest permanent grassland patch (ha), PG edges: permanent grassland edges $(\mathrm{km}), \% \mathrm{WH}$ : proportion of wooded habitat (\%), WH edges: wooded habitat edges $(\mathrm{km}), \%$ crops: proportion of crop (\%)

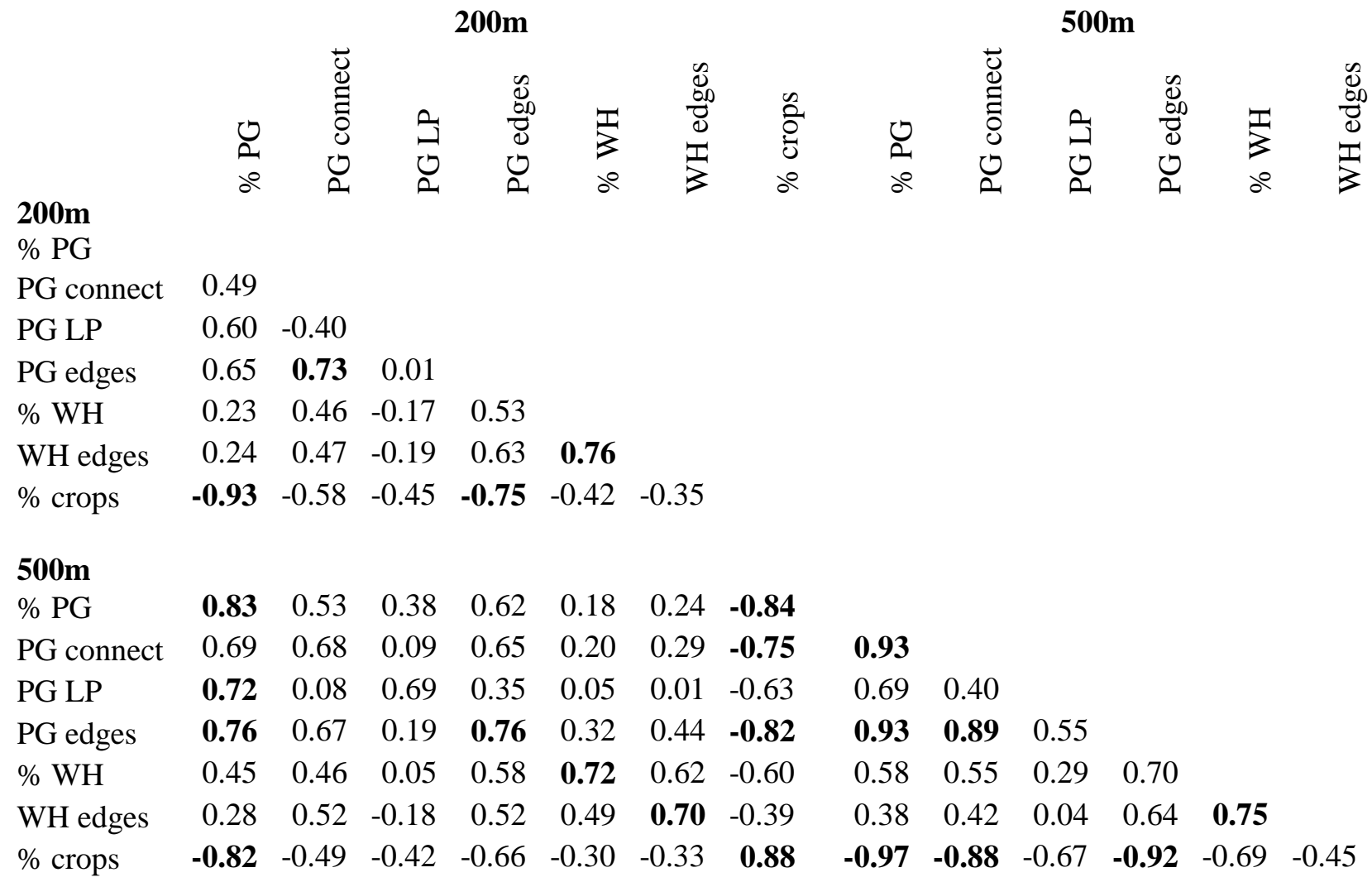




\section{Appendix 1J}

List of landscape descriptors retained for regression models after the random forest procedure for each plant biodiversity measure. The retained variable are those whose relative importance value was higher than the absolute importance value of the lowest negative-scoring landscape descriptor.

\begin{tabular}{|c|c|c|c|c|c|c|c|c|c|c|c|c|c|c|}
\hline & \multicolumn{7}{|c|}{$200 \mathrm{~m}$} & \multicolumn{7}{|c|}{$500 \mathrm{~m}$} \\
\hline Biodiversity measure & $\begin{array}{l}0 \\
2 \\
0\end{array}$ & $\begin{array}{l}\text { U⿺ } \\
\ddot{\Xi} \\
0 \\
0 \\
0\end{array}$ & $\begin{array}{l}a \\
\vdots \\
0\end{array}$ & $\begin{array}{l}0 \\
0 \\
0 \\
0 \\
0 \\
0\end{array}$ & $\begin{array}{l}\frac{1}{3} \\
\delta^{\circ}\end{array}$ & 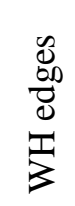 & 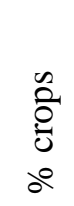 & $\begin{array}{l}0 \\
0 \\
0\end{array}$ & 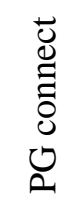 & $\begin{array}{l}\vec{a} \\
0 \\
0\end{array}$ & $\begin{array}{l}\mathscr{U} \\
8 \\
8 \\
0 \\
0\end{array}$ & $\begin{array}{l}1 \\
3 \\
8\end{array}$ & $\begin{array}{l}0 \\
\mathbb{8} \\
0 \\
0 \\
0 \\
1 \\
3\end{array}$ & 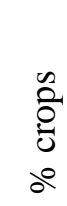 \\
\hline all species richness & & & & & & $x$ & & & $x$ & & & & $x$ & \\
\hline forest richness & & & & & & & & $x$ & $x$ & & $x$ & & & $x$ \\
\hline grassland richness & & & & & & $x$ & & & $x$ & & & & $x$ & \\
\hline ruderal richness & & & $\mathrm{x}$ & & & & $\mathrm{x}$ & $x$ & & & & & & \\
\hline anemochorous richne & & & & & & & & & & & & & & \\
\hline barochorous richness & & & & & & & & & & & $\mathrm{X}$ & & $x$ & $\mathrm{x}$ \\
\hline zoochorous richness & & & & & & $x$ & & & & & $x$ & & & \\
\hline
\end{tabular}




\section{Appendix 1K}

List of landscape descriptors retained for regression models after the random forest procedure for each carabid biodiversity measure. The retained variable are those whose relative importance value was higher than the absolute importance value of the lowest negative-scoring landscape descriptor.

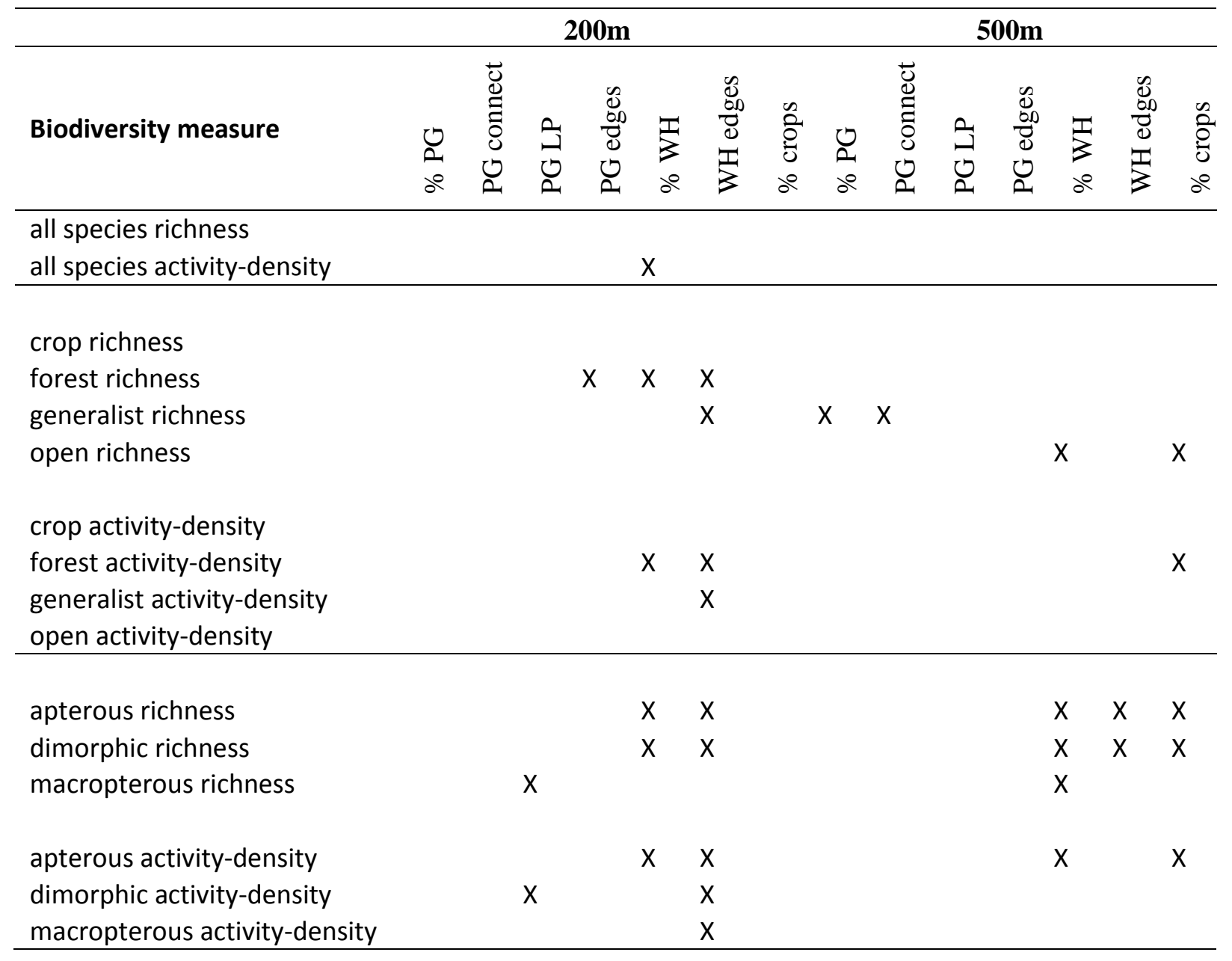




\section{Appendix 1L}

List of landscape descriptors retained for regression models after the random forest procedure for each bird biodiversity measure. The retained variable are those whose relative importance value was higher than the absolute importance value of the lowest negative-scoring landscape descriptor.

\begin{tabular}{|c|c|c|c|c|c|c|c|c|c|c|c|c|c|c|}
\hline & \multicolumn{7}{|c|}{$200 \mathrm{~m}$} & \multicolumn{7}{|c|}{$500 \mathrm{~m}$} \\
\hline Biodiversity measure & $\begin{array}{l}0 \\
2 \\
\text { o }\end{array}$ & 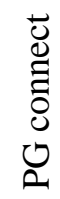 & $\begin{array}{l}\vec{a} \\
0 \\
0\end{array}$ & $\begin{array}{l}0 \\
\mathbb{8} \\
8 \\
0 \\
0 \\
0\end{array}$ & $\begin{array}{l}\frac{1}{3} \\
80\end{array}$ & $\begin{array}{l}0 \\
0 \\
0 \\
0 \\
0 \\
I \\
3\end{array}$ & $\begin{array}{l}\text { 岂 } \\
\text { ర0 } \\
0^{\circ}\end{array}$ & $\begin{array}{l}0 \\
\delta^{\circ}\end{array}$ & 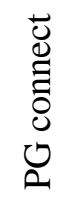 & $\begin{array}{l}a \\
0 \\
0\end{array}$ & $\begin{array}{l}0 \\
0 \\
0 \\
0 \\
0 \\
0\end{array}$ & $\begin{array}{l}\frac{1}{3} \\
0^{\circ}\end{array}$ & $\begin{array}{l}\mathscr{0} \\
\stackrel{\infty}{0} \\
\mathbb{8} \\
\mathbb{I}\end{array}$ & 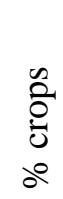 \\
\hline all species total richness & & & & & & $x$ & & & & & & & & \\
\hline all species richness of nester & & & & & $x$ & $x$ & & & & & & & & \\
\hline all species abundance of nester & & & & & $x$ & $x$ & & & & & & $x$ & & \\
\hline forest total richness & & $\mathrm{X}$ & $x$ & & & $\mathrm{X}$ & & & & & & & $\mathrm{X}$ & \\
\hline generalist total richness & & & & & $x$ & $x$ & & & & & & $x$ & $x$ & \\
\hline farmland total richness & & & & & & & & $x$ & $x$ & & & & & \\
\hline forest richness of nester & & & & & $x$ & $x$ & & & & & & $x$ & $x$ & \\
\hline generalist richness of nester & & & & & & & & & & & & $x$ & $x$ & \\
\hline farmland richness of nester & & & & & & & & & & & $x$ & $x$ & $\mathrm{X}$ & \\
\hline forest abundance of nester & & & & & $x$ & $x$ & & & & & & $x$ & & \\
\hline generalist abundance of nester & & & & & $x$ & $x$ & & & & & & $x$ & $X$ & \\
\hline farmland abundance of nester & & & & & & & & & & & & $x$ & $\mathrm{X}$ & \\
\hline \multicolumn{15}{|l|}{ low richness } \\
\hline medium richness & & & $x$ & & $x$ & & & & & & & & & \\
\hline high richness & & & & & $x$ & $x$ & & & & & & & & \\
\hline low richness of nester & & & & & & & & & & & & & $x$ & \\
\hline medium richness of nester & & & & & & & & & & & & & & \\
\hline high richness of nester & & & & $x$ & $x$ & $x$ & & & & & & & & \\
\hline low abundance of nester & & & & & & $x$ & & & & & & & & \\
\hline medium abundance of nester & & & & & $x$ & $x$ & & & & & & & & \\
\hline high abundance of nester & & & & & $x$ & $x$ & & & & & & & & \\
\hline
\end{tabular}




\section{Appendix 1M}

Estimate and 95\% confidence intervals from model averaging for plant biodiversity measures. Significant results, i.e. estimates whose $95 \%$ confidence interval do not include zero, are in bold. Near significant results are shown with a " $X$ " sign. All models were performed using a Gaussian distribution except for biodiversity measures with *, for which Poisson distribution was used, and with ${ }^{* *}$ for which a negative binomial distribution was used. Models with only intercept values indicate a null model, i.e. random forest procedure selected no landscape descriptors (see "2.4 Statistical analyses"). Landscape descriptors: \% PG: proportion of permanent grassland, PG connect: permanent grassland connectivity index, PG LP: largest permanent grassland patch (ha), PG edges: permanent grassland edges, $\% \mathrm{WH}$ : proportion of wooded habitat, $\mathrm{WH}$ edges: wooded habitat edges, \% crops: proportion of crop. " $200 \mathrm{~m}$ " and " $500 \mathrm{~m}$ " indicate the scale at which the considered landscape descriptor was measured.

\begin{tabular}{llccc}
\hline biodiversity measure & landscape descriptor & estimates & lower Cl & upper CI \\
\hline allspecies richness & (Intercept) & 14,74 & 11,941 & 17,547 \\
& WH edges 200m & $\mathbf{2 , 0 5}$ & $\mathbf{0 , 1 2 3}$ & $\mathbf{3 , 9 8 3}$ \\
& PG connect 500m & 0,97 & $-0,734$ & 2,678 \\
& WH edges 500m & 0,64 & $-2,046$ & 3,321 \\
\hline forest richness * & (Intercept) & $-0,42$ & $-0,762$ & $-0,074$ \\
& PG edges 500m & 0,33 & $-0,183$ & 0,839 \\
& PG connect 500m & 0,32 & $-0,180$ & 0,821 \\
& \% crops 500m & $-0,25$ & $-0,777$ & 0,267 \\
& \% PG 500m & 0,17 & $-0,394$ & 0,729 \\
grassland richness & (Intercept) & 12,14 & 10,261 & 14,024 \\
& WH edges 200m & $\mathbf{1 , 9 7}$ & $\mathbf{0 , 4 8 8}$ & $\mathbf{3 , 4 4 3}$ \\
& PG connect 500m & 0,66 & $-0,667$ & 1,986 \\
ruderal richness ** & WH edges 500m & 0,12 & $-1,826$ & 2,072 \\
& (Intercept) & 0,49 & 0,036 & 0,940 \\
& PG LP 200m & 0,15 & $-0,091$ & 0,400 \\
& \% crops 200m & $-0,15$ & $-0,413$ & 0,113 \\
& \% PG 500m & 0,02 & $-0,248$ & 0,288 \\
\hline anemochor richness * & (Intercept) & 1,03 & 0,849 & 1,189 \\
barochor richness * & (Intercept) & 1,67 & 1,451 & 1,887 \\
& WH edges 500m & 0,15 & $-0,006$ & 0,306 \\
& \% crops 500m & $-0,08$ & $-0,257$ & 0,089 \\
& PG edges 500m & 0,03 & $-0,195$ & 0,248 \\
& (Intercept) & 6,38 & 5,208 & $\mathbf{7 , 5 5 0}$ \\
& WH edges 200m & $\mathbf{1 , 3 6}$ & $\mathbf{0 , 5 7 7}$ & $\mathbf{2 , 1 3 4}$ \\
zoochor richness & PG edges 500m & 0,34 & $-0,461$ & 1,142 \\
\hline
\end{tabular}




\section{Appendix 1N}

Estimate and 95\% confidence intervals from model averaging for carabid biodiversity measures. Significant results, i.e. estimates whose confidence interval do not include zero, are in bold. Near significant results are shown with a " $X$ " sign. All models were performed using a negative binomial distribution except for biodiversity measures with ${ }^{*}$, for which a Gaussian distribution was used and ${ }^{* *}$ for which a Poisson distribution was used. Models with only intercept values indicate a null model, i.e. random forest procedure selected no landscape descriptors (see "2.4. Statistical analyses"). Landscape descriptors: \% PG: proportion of permanent grassland, PG connect: permanent grassland connectivity index, PG LP: largest permanent grassland patch (ha), PG edges: permanent grassland edges, $\% \mathrm{WH}$ : proportion of wooded habitat, WH edges: wooded habitat edges, \% crops: proportion of crop. " $200 \mathrm{~m}$ " and " $500 \mathrm{~m}$ " indicate the scale at which the considered landscape descriptor was measured.

\begin{tabular}{|c|c|c|c|c|}
\hline biodiversity measure & landscape descriptor & estimates & lower $\mathrm{Cl}$ & upper $\mathrm{Cl}$ \\
\hline allspecies richness & (Intercept) & 3,02 & 2,890 & 3,153 \\
\hline \multirow[t]{2}{*}{ activity-density } & (Intercept) & 1,42 & 1,224 & 1,616 \\
\hline & $\%$ WH $200 m$ & 0,18 & $-0,029$ & 0,391 \\
\hline crop richness & (Intercept) & 1,05 & 0,803 & 1,289 \\
\hline activity-density $* *$ & (Intercept) & $-0,98$ & $-1,817$ & $-0,514$ \\
\hline \multirow[t]{4}{*}{ forest richness } & (Intercept) & 0,79 & 0,39 & 1,18 \\
\hline & WH edges $200 \mathrm{~m}$ & 0,38 & $-0,02$ & 0,78 \\
\hline & $\%$ WH $200 \mathrm{~m}$ & 0,33 & $-0,068$ & 0,738 \\
\hline & PG edges $200 \mathrm{~m}$ & 0,15 & $-0,235$ & 0,534 \\
\hline \multirow[t]{4}{*}{ activity-density } & (Intercept) & $-1,08$ & $-1,802$ & $-0,367$ \\
\hline & $\%$ WH 200m & 0,56 & 0,015 & 1,108 \\
\hline & $\%$ crops $500 m$ & $-0,42$ & $-1,050$ & 0,203 \\
\hline & WH edges $200 \mathrm{~m}$ & 0,45 & $-0,309$ & 1,200 \\
\hline \multirow[t]{4}{*}{ generalist richness * } & (Intercept) & 4,18 & 3,456 & 4,894 \\
\hline & WH edges $200 \mathrm{~m}$ & 0,45 & $-0,262$ & 1,155 \\
\hline & PG connect $500 \mathrm{~m}$ & $-0,36$ & $-1,087$ & 0,366 \\
\hline & $\%$ PG 500m & $-0,11$ & $-0,839$ & 0,629 \\
\hline \multirow[t]{2}{*}{ activity-density } & (Intercept) & 0,18 & $-0,210$ & 0,561 \\
\hline & WH edges $200 \mathrm{~m}$ & 0,42 & 0,078 & 0,765 \\
\hline \multirow[t]{3}{*}{ open richness } & (Intercept) & 2,23 & 2,050 & 2,410 \\
\hline & $\%$ crops $500 m$ & 0,20 & $-0,028$ & 0,435 \\
\hline & $\%$ WH 500m & $-0,13$ & $-0,416$ & 0,157 \\
\hline activity-density & (Intercept) & 0,55 & 0,204 & 0,814 \\
\hline \multirow[t]{6}{*}{ apterous richness } & (Intercept) & 0,82 & 0,490 & 1,147 \\
\hline & WH edges $200 \mathrm{~m}$ & 0,31 & $-0,064$ & 0,692 \\
\hline & $\%$ WH 500m & 0,24 & $-0,113$ & 0,592 \\
\hline & $\%$ WH 200m & 0,27 & $-0,112$ & 0,648 \\
\hline & $\%$ crops $500 m$ & $-0,21$ & $-0,563$ & 0,147 \\
\hline & WH edges $500 \mathrm{~m}$ & 0,23 & $-0,178$ & 0,643 \\
\hline
\end{tabular}




\begin{tabular}{clccc} 
activity-density & (Intercept) & $-1,11$ & $-1,834$ & $-0,389$ \\
& \% WH 200m & 0,51 & $-0,063$ & 1,089 \\
& \% crops 500m & $-0,48$ & $-1,147$ & 0,192 \\
& WH edges 200m & 0,40 & $-0,343$ & 1,151 \\
\% WH 500m & 0,30 & $-0,513$ & 1,112 \\
dimorphic richness * & (Intercept) & 5,90 & 4,737 & 7,063 \\
& WH edges 200m & $-1,38$ & $-3,003$ & 0,234 \\
& \% crops 500m & 0,94 & $-0,700$ & 2,587 \\
& \% WH 500m & $-0,62$ & $-2,479$ & 1,243 \\
& WH edges 500m & $-0,76$ & $-2,568$ & 1,058 \\
activity-density & \% WH 200m & $-0,16$ & $-2,069$ & 1,741 \\
& (Intercept) & 0,11 & $-0,279$ & 0,505 \\
& WH edges 200m & $-0,31$ & $-0,649$ & 0,023 \\
macropterous richness & PG LP 200m & 0,06 & $-0,295$ & 0,405 \\
& (Intercept) & 2,47 & 2,293 & 2,645 \\
& PG LP 200m & $-0,14$ & $-0,323$ & 0,049 \\
& \% WH 500m & $-0,10$ & $-0,290$ & 0,081 \\
& (Intercept) & 0,84 & 0,583 & 1,105 \\
& WH edges 200m & $\mathbf{0 , 3 4}$ & $\mathbf{0 , 0 8 6}$ & $\mathbf{0 , 5 8 6}$ \\
\hline
\end{tabular}




\section{Appendix 10}

Estimate and 95\% confidence intervals from model averaging for bird biodiversity measures (all species and habitat affinity). Significant results, i.e. estimates whose $95 \%$ confidence interval do not include zero, are in bold. Near significant results are shown with a " $X$ " sign. All models were performed using a Gaussian distribution except for biodiversity measures with *, for which a Poisson distribution was used. Models with only intercept values indicate a null model, i.e. random forest procedure selected no landscape descriptors (see "2.4. Statistical analyses"). Landscape descriptors: \% PG: proportion of permanent grassland, PG connect: permanent grassland connectivity index, PG LP: largest permanent grassland patch (ha), PG edges: permanent grassland edges, \% WH: proportion of wooded habitat, WH edges: wooded habitat edges, \% crops: proportion of crop. " $200 \mathrm{~m}$ " and " $500 \mathrm{~m}$ " indicate the scale at which the considered landscape descriptor was measured.

\begin{tabular}{|c|c|c|c|c|}
\hline biodiversity measure & Landscape descriptor & estimates & lower Cl & upper $\mathrm{Cl}$ \\
\hline \multirow[t]{5}{*}{ all species total richness } & (Intercept) & 24,29 & 22,623 & 25,949 \\
\hline & WH edges $200 \mathrm{~m}$ & 1,18 & $-0,508$ & 2,863 \\
\hline & (Intercept) & 15,87 & 14,869 & 16,865 \\
\hline & $\% \mathrm{WH} 200 \mathrm{~m}$ & 0,59 & $-0,270$ & 1,459 \\
\hline & WH edges $200 \mathrm{~m}$ & 0,52 & $-0,381$ & 1,431 \\
\hline \multirow[t]{4}{*}{ abundance of nester } & (Intercept) & 25,81 & 24,27 & 27,35 \\
\hline & $\%$ WH 200m & 2,01 & $-0,31$ & 4,32 \\
\hline & WH edges $200 \mathrm{~m}$ & 1,60 & $-0,76$ & 3,95 \\
\hline & $\%$ WH 500m & $-0,39$ & $-2,70$ & 1,92 \\
\hline \multirow[t]{5}{*}{ forest total richness } & (Intercept) & 7,10 & 6,345 & 7,845 \\
\hline & PG LP 200m & $-0,76$ & $-1,526$ & 0,009 \\
\hline & WH edges $200 \mathrm{~m}$ & 0,66 & $-0,155$ & 1,483 \\
\hline & PG connect $200 \mathrm{~m}$ & 0,52 & $-0,338$ & 1,381 \\
\hline & WH edges $500 \mathrm{~m}$ & 0,30 & $-0,666$ & 1,269 \\
\hline \multirow[t]{5}{*}{ richness of nester } & (Intercept) & 4,38 & 3,934 & 4,827 \\
\hline & WH edges $200 \mathrm{~m}$ & 0,85 & 0,238 & 1,456 \\
\hline & $\%$ WH $200 m$ & 0,74 & $-0,018$ & 1,504 \\
\hline & $\%$ WH $500 \mathrm{~m}$ & $-0,30$ & $-0,947$ & 0,349 \\
\hline & WH edges $500 \mathrm{~m}$ & $-0,19$ & $-0,840$ & 0,455 \\
\hline \multirow[t]{4}{*}{ abundance of nester } & (Intercept) & 7,43 & 5,151 & 9,710 \\
\hline & $\%$ WH 200m & 1,76 & 0,786 & 2,734 \\
\hline & WH edges $200 \mathrm{~m}$ & 0,38 & $-0,79$ & 1,56 \\
\hline & $\% \mathrm{WH} 500 \mathrm{~m}$ & $-0,25$ & $-1,432$ & 0,924 \\
\hline \multirow[t]{5}{*}{ generalist total richness } & (Intercept) & 10,14 & 9,639 & 10,647 \\
\hline & WH edges $200 \mathrm{~m}$ & 0,81 & 0,111 & 1,501 \\
\hline & $\%$ WH $200 m$ & 0,62 & $-0,099$ & 1,330 \\
\hline & WH edges $500 \mathrm{~m}$ & $-0,44$ & $-1,148$ & 0,268 \\
\hline & $\%$ WH 500m & $-0,03$ & $-0,699$ & 0,647 \\
\hline \multirow[t]{3}{*}{ richness of nester* } & (Intercept) & 2,08 & 1,924 & 2,246 \\
\hline & WH edges $500 \mathrm{~m}$ & 0,05 & $-0,116$ & 0,210 \\
\hline & $\%$ WH 500m & 0,04 & $-0,118$ & 0,207 \\
\hline
\end{tabular}




\begin{tabular}{clccc} 
abundance of nester & (Intercept) & 14,48 & 13,50 & 15,46 \\
& WH edges 200m & 1,19 & $-0,02$ & 2,40 \\
& \% WH 200m & 0,63 & $-0,90$ & 2,15 \\
& \% WH 500m & 0,67 & $-0,68$ & 2,01 \\
& WH edges 500m & 0,27 & $-1,269$ & 1,818 \\
\hline farmland total richness* & (Intercept) & 1,55 & 1,338 & 1,760 \\
& PG connect 500m & 0,09 & $-0,116$ & 0,300 \\
& \% PG 500m & 0,08 & $-0,132$ & 0,287 \\
richness of nester & (Intercept) & 2,76 & 2,330 & 3,194 \\
& WH edges 500m & $-0,62$ & $-1,096$ & $-0,153$ \\
& \% WH 500m & $-0,40$ & $-1,058$ & 0,250 \\
& PG edges 500m & - & - & - \\
abundance of nester & (Intercept) & 3,14 & 2,631 & 3,655 \\
& WH edges 500m & $-\mathbf{0 , 8 2}$ & $-\mathbf{1 , 3 8 9}$ & $-\mathbf{0 , 2 4 8}$ \\
& \% WH 500m & $-0,40$ & $-1,282$ & 0,478 \\
\hline
\end{tabular}




\section{Appendix 1P}

Estimate and 95\% confidence intervals from model averaging for bird biodiversity measures (dispersal ability). Significant results, i.e. estimates whose confidence interval do not include zero, are in bold. All models were performed using a Gaussian distribution. Models with only intercept values indicate a null model, i.e. random forest procedure selected no landscape descriptors (see "2.4. Statistical analyses"). Landscape descriptors: \% PG: proportion of permanent grassland, PG connect: permanent grassland connectivity index, PG LP: largest permanent grassland patch (ha), PG edges: permanent grassland edges, \% WH: proportion of wooded habitat, WH edges: wooded habitat edges, \% crops: proportion of crop. "200m" and " $500 \mathrm{~m}$ " indicate the scale at which the considered landscape descriptor was measured.

\begin{tabular}{clccc}
\hline Biodiversity measure & landscape descriptor & estimates & lower Cl & upper Cl \\
\hline low total richness & (Intercept) & 6.81 & 6.281 & 7.338 \\
richness of nester & (Intercept) & 5.76 & 5.297 & 6.230 \\
& WH edges 500m & 0.36 & -0.058 & 0.781 \\
abundance of nester & (Intercept) & 9.81 & 8.970 & 10.649 \\
& WH edges 200m & 0.66 & -0.184 & 1.501 \\
\hline medium total richness & (Intercept) & 8.43 & 7.754 & 9.104 \\
& PG LP 200m & -0.66 & -1.332 & 0.013 \\
richness of nester & \% WH 200m & 0.39 & -0.314 & 1.098 \\
abundance of nester & (Intercept) & 6.33 & 5.828 & 6.906 \\
& (Intercept) & 11.43 & 10.339 & 12.518 \\
& \% WH 200m & $\mathbf{1 . 3 8}$ & $\mathbf{0 . 0 8 7}$ & $\mathbf{2 . 6 8 2}$ \\
& WH edges 200m & 0.08 & -1.811 & 1.974 \\
\hline high total richness & (Intercept) & 5.48 & 4.820 & 6.132 \\
& WH edges 200m & 0.52 & -0.276 & 1.323 \\
richness of nester & \% WH 200m & -0.07 & -1.078 & 0.942 \\
& (Intercept) & 2.62 & 2.129 & 3.109 \\
& WH edges 200m & $\mathbf{0 . 6 7}$ & $\mathbf{0 . 0 4 6}$ & $\mathbf{1 . 2 9 2}$ \\
& \% WH 200m & 0.62 & -0.004 & 1.254 \\
& PG edges 200m & -0.19 & -0.838 & 0.467 \\
abundance of nester & (Intercept) & 3.33 & 2.588 & 4.078 \\
& \% WH 200m & 0.85 & -0.060 & 1.761 \\
& WH edges 200m & 0.76 & -0.217 & 1.745 \\
\hline
\end{tabular}




\section{Appendix 2A}

Corrected Akaike information criterion $\left(\mathrm{AIC}_{\mathrm{c}}\right), \mathrm{AIC}_{\mathrm{c}}$ difference with best model $\left(\triangle \mathrm{AIC} \mathrm{C}_{\mathrm{c}}\right)$, and Akaike weights $\left(w_{i}\right)$ of all supported models $\left(\Delta \mathrm{AIC} \mathrm{C}_{\mathrm{c}}<\right.$ 4 ) that were included in model averaging for the analysis of plant biodiversity measures. Models are ordered in terms of $\Delta \mathrm{AIC}_{\mathrm{c}}$. In bold are the biodiversity measures with significant effects detected. \% PG: proportion of permanent grassland (\%), PG connect: permanent grassland connectivity index, PG LP: largest permanent grassland patch (ha), PG edges: permanent grassland edges (km), \% WH: proportion of wooded habitat (\%), WH edges: wooded habitat edges $(\mathrm{km})$, \% crops: proportion of crop (\%)

\begin{tabular}{|c|c|c|c|c|c|c|c|c|c|c|c|c|}
\hline Biodiversity measure & 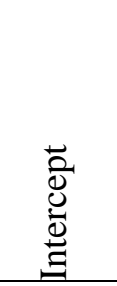 & 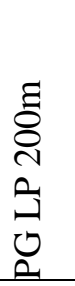 & 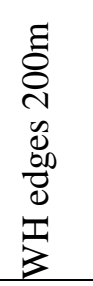 & 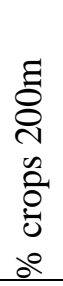 & $\begin{array}{l}\text { E } \\
0 \\
0 \\
0 \\
0 \\
0 \\
0\end{array}$ & $\begin{array}{l}\tilde{\Xi} \\
\delta \\
0 \\
\tilde{U} \\
0 \\
\tilde{\Xi}\end{array}$ & 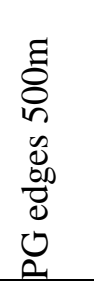 & 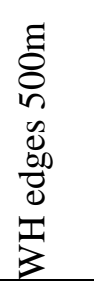 & $\begin{array}{l}\text { E } \\
8 \\
0 \\
0 \\
0 \\
0 \\
0 \\
0 \\
0\end{array}$ & $\mathrm{AlC}_{\mathrm{c}}$ & $\Delta \mathrm{AlC}_{\mathrm{c}}$ & $w_{i}$ \\
\hline \multirow[t]{6}{*}{ allspecies richness } & 14.77 & & 2.03 & & & 0.99 & & & & 345.7 & 0 & 0.25 \\
\hline & 14.76 & & 1.99 & & & 0.97 & & 0.08 & & 345.9 & 0.20 & 0.23 \\
\hline & 14.69 & & 1.92 & & & & & 0.61 & & 346.1 & 0.45 & 0.20 \\
\hline & 14.76 & & 2.30 & & & & & & & 346.2 & 0.47 & 0.20 \\
\hline & 14.75 & & & & & 0.90 & & 1.56 & & 348.6 & 2.88 & 0.06 \\
\hline & 14.68 & & & & & & & 2.02 & & 348.7 & 3.04 & 0.06 \\
\hline \multirow[t]{10}{*}{ forest richness } & -0.42 & & & & & & 0.38 & & & 119.6 & 0 & 0.19 \\
\hline & -0.42 & & & & & 0.38 & & & & 119.7 & 0.04 & 0.19 \\
\hline & -0.41 & & & & & & & & -0.37 & 120.3 & 0.68 & 0.14 \\
\hline & -0.40 & & & & 0.33 & & & & & 120.9 & 1.25 & 0.10 \\
\hline & -0.43 & & & & & 0.25 & & & -0.17 & 121.6 & 1.93 & 0.07 \\
\hline & -0.43 & & & & & 0.20 & 0.21 & & & 121.6 & 1.94 & 0.07 \\
\hline & -0.42 & & & & & & 0.28 & & -0.11 & 121.9 & 2.21 & 0.06 \\
\hline & -0.42 & & & & 0.04 & & 0.34 & & & 122.0 & 2.31 & 0.06 \\
\hline & -0.42 & & & & 0.05 & 0.34 & & & & 122.0 & 2.35 & 0.06 \\
\hline & -0.42 & & & & 0.12 & & & & -0.26 & 122.4 & 2.80 & 0.05 \\
\hline
\end{tabular}




\begin{tabular}{|c|c|c|c|c|c|c|c|c|c|c|c|c|}
\hline \multirow[t]{4}{*}{ grassland richness } & 12.15 & & 2.08 & & & & & & & 320.5 & 0 & 0.33 \\
\hline & 12.15 & & 1.89 & & & 0.65 & & & & 321.0 & 0.46 & 0.26 \\
\hline & 12.12 & & 1.90 & & & & & 0.28 & & 321.2 & 0.66 & 0.23 \\
\hline & 12.15 & & 1.94 & & & 0.67 & & -0.08 & & 321.7 & 1.17 & 0.18 \\
\hline \multirow[t]{7}{*}{ ruderal richness } & 0.50 & & & & & & & & & 190.7 & 0 & 0.24 \\
\hline & 0.49 & 0.17 & & & & & & & & 190.8 & 0.13 & 0.23 \\
\hline & 0.47 & & & -0.16 & & & & & & 191.0 & 0.32 & 0.21 \\
\hline & 0.50 & & & & 0.08 & & & & & 192.4 & 1.75 & 0.10 \\
\hline & 0.48 & 0.11 & & -0.10 & & & & & & 192.7 & 2.06 & 0.09 \\
\hline & 0.49 & 0.17 & & & 0.00 & & & & & 193.2 & 2.55 & 0.07 \\
\hline & 0.47 & & & -0.20 & -0.05 & & & & & 193.3 & 2.63 & 0.07 \\
\hline anemochor richness & 1.03 & & & & & & & & & 199.7 & & \\
\hline \multirow[t]{7}{*}{ barochor richness } & 1.66 & & & & & & & 0.16 & & 249.6 & 0 & 0.38 \\
\hline & 1.66 & & & & & & & 0.13 & -0.05 & 251.5 & 1.88 & 0.15 \\
\hline & 1.68 & & & & & & & & -0.11 & 251.7 & 2.08 & 0.13 \\
\hline & 1.66 & & & & & & 0.02 & 0.15 & & 251.9 & 2.27 & 0.12 \\
\hline & 1.69 & & & & & & 0.10 & & & 252.4 & 2.81 & 0.09 \\
\hline & 1.70 & & & & & & & & & 252.7 & 3.11 & 0.08 \\
\hline & 1.66 & & & & & & -0.08 & 0.15 & -0.11 & 253.6 & 3.94 & 0.05 \\
\hline \multirow[t]{2}{*}{ zoochor richness } & 6.38 & & 1.39 & & & & & & & 268.5 & 0 & 0.70 \\
\hline & 6.38 & & 1.26 & & & & 0.34 & & & 270.2 & 1.71 & 0.30 \\
\hline
\end{tabular}




\section{Appendix 2B}

Corrected Akaike information criterion $\left(\mathrm{AIC}_{\mathrm{c}}\right), \mathrm{AIC}_{\mathrm{c}}$ difference with best model $\left(\triangle \mathrm{AIC} \mathrm{C}_{\mathrm{c}}\right)$, and Akaike weights $\left(w_{i}\right)$ of all supported models $\left(\Delta \mathrm{AIC} \mathrm{C}_{\mathrm{c}}<\right.$ 4 ) that were included in model averaging for the analysis of carabid biodiversity measures. Models are ordered in terms of $\triangle \mathrm{AIC}_{\mathrm{c}}$. In bold are the biodiversity measures with significant effects detected. \% PG: proportion of permanent grassland (\%), PG connect: permanent grassland connectivity index, PG LP: largest permanent grassland patch (ha), PG edges: permanent grassland edges (km), \% WH: proportion of wooded habitat (\%), WH edges: wooded habitat edges ( $\mathrm{km})$, \% crops: proportion of crop (\%)

\begin{tabular}{|c|c|c|c|c|c|c|c|c|c|c|c|c|c|}
\hline Biodiversity measure & $\begin{array}{l}\overrightarrow{0} \\
\stackrel{\overrightarrow{0}}{0} \\
\stackrel{0}{\vec{J}} \\
\stackrel{\Xi}{\Xi}\end{array}$ & 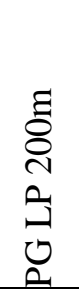 & $\begin{array}{l}\Xi \\
8 \\
0 \\
0 \\
0 \\
0 \\
0 \\
0 \\
0 \\
0\end{array}$ & 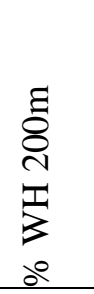 & 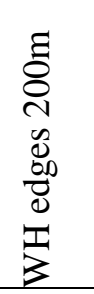 & $\begin{array}{l}\text { E్ } \\
8 \\
0 \\
0 \\
0 \\
0\end{array}$ & $\begin{array}{l}\tilde{\Xi} \\
0 \\
0 \\
0 \\
0 \\
0 \\
0 \\
0 \\
0 \\
2\end{array}$ & 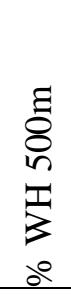 & 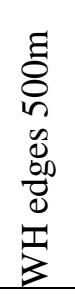 & $\begin{array}{l}\Xi \\
\delta \\
0 \\
0 \\
0 \\
0 \\
0 \\
0 \\
0\end{array}$ & $\mathrm{AIC}_{\mathrm{c}}$ & $\Delta \mathrm{AlC}_{\mathrm{c}}$ & $w_{i}$ \\
\hline allspecies richness & 3.02 & & & & & & & & & & 288.7 & & \\
\hline \multirow[t]{2}{*}{ activity-density } & 1.41 & & & 0.18 & & & & & & & 194.2 & 0 & 0.65 \\
\hline & 1.43 & & & & & & & & & & 195.4 & 1.26 & 0.35 \\
\hline crop richness & 1.05 & & & & & & & & & & 173.5 & & \\
\hline activity-density & -0.98 & & & & & & & & & & 69.3 & & \\
\hline \multirow[t]{7}{*}{ forest richness } & 0.78 & & & & 0.43 & & & & & & 174.3 & 0 & 0.33 \\
\hline & 0.80 & & & 0.40 & & & & & & & 174.9 & 0.61 & 0.24 \\
\hline & 0.78 & & & 0.22 & 0.28 & & & & & & 176.0 & 1.68 & 0.14 \\
\hline & 0.78 & & 0.11 & & 0.38 & & & & & & 176.6 & 2.28 & 0.10 \\
\hline & 0.80 & & 0.14 & 0.35 & & & & & & & 177.0 & 2.65 & 0.09 \\
\hline & 0.79 & & & & & & & & & & 178.0 & 3.71 & 0.05 \\
\hline & 0.79 & & 0.27 & & & & & & & & 178.2 & 3.94 & 0.05 \\
\hline \multirow[t]{4}{*}{ activity-density } & -1.06 & & & 0.61 & & & & & & & 76.5 & 0 & 0.33 \\
\hline & -1.09 & & & 0.49 & & & & & & -0.30 & 78.1 & 1.67 & 0.14 \\
\hline & -1.10 & & & & 0.60 & & & & & & 78.5 & 2.00 & 0.12 \\
\hline & -1.11 & & & & & & & & & -0.55 & 78.5 & 2.01 & 0.12 \\
\hline
\end{tabular}




\begin{tabular}{|c|c|c|c|c|c|c|c|c|c|c|c|}
\hline & -1.16 & & 0.49 & & & & & -0.44 & 78.6 & 2.12 & 0.12 \\
\hline & -1.09 & 0.50 & 0.22 & & & & & & 78.8 & 2.30 & 0.11 \\
\hline & -1.00 & & & & & & & & 80.0 & 3.57 & 0.06 \\
\hline \multirow[t]{6}{*}{ generalist richness } & 4.18 & & & & & & & & 179.5 & 0 & 0.38 \\
\hline & 4.18 & & 0.43 & & & & & & 180.7 & 1.22 & 0.21 \\
\hline & 4.18 & & & & -0.34 & & & & 181.3 & 1.82 & 0.15 \\
\hline & 4.18 & & & -0.09 & & & & & 182.1 & 2.63 & 0.10 \\
\hline & 4.18 & & 0.48 & & $-0.4 C$ & & & & 182.3 & 2.81 & 0.09 \\
\hline & 4.18 & & 0.45 & -0.14 & & & & & 183.4 & 3.91 & 0.05 \\
\hline activity-density & 0.17 & & 0.42 & & & & & & 124.7 & 0 & 1.00 \\
\hline \multirow[t]{4}{*}{ open richness } & 2.23 & & & & & & & 0.21 & 246.5 & 0 & 0.47 \\
\hline & 2.23 & & & & & -0.18 & & & 247.7 & 1.26 & 0.25 \\
\hline & 2.24 & & & & & & & & 248.7 & 2.25 & 0.15 \\
\hline & 2.23 & & & & & -0.03 & & 0.18 & 249.0 & 2.59 & 0.13 \\
\hline activity-density & 0.55 & & & & & & & & 142.7 & & \\
\hline \multirow[t]{15}{*}{ apterous richness } & 0.81 & & 0.33 & & & 0.24 & & & 168.8 & 0 & 0.10 \\
\hline & 0.85 & 0.38 & & & & & & & 169.0 & 0.21 & 0.09 \\
\hline & 0.82 & & 0.40 & & & & & & 169.1 & 0.25 & 0.09 \\
\hline & 0.81 & & 0.35 & & & & & -0.23 & 169.1 & 0.27 & 0.09 \\
\hline & 0.80 & & & & & 0.27 & 0.29 & & 169.7 & 0.91 & 0.06 \\
\hline & 0.83 & 0.23 & 0.24 & & & & & & 170.2 & 1.37 & 0.05 \\
\hline & 0.83 & 0.29 & & & & 0.19 & & & 170.2 & 1.39 & 0.05 \\
\hline & 0.81 & & & & & & 0.31 & -0.26 & 170.2 & 1.39 & 0.05 \\
\hline & 0.80 & & & & & 0.35 & & & 170.3 & 1.46 & 0.05 \\
\hline & 0.84 & 0.31 & & & & & & -0.17 & 170.4 & 1.56 & 0.04 \\
\hline & 0.84 & 0.29 & & & & & 0.19 & & 170.5 & 1.71 & 0.04 \\
\hline & 0.82 & & & & & & 0.37 & & 170.8 & 1.94 & 0.04 \\
\hline & 0.81 & & & & & & & -0.32 & 171.3 & 2.46 & 0.03 \\
\hline & 0.80 & & 0.24 & & & 0.24 & 0.12 & & 171.3 & 2.50 & 0.03 \\
\hline & 0.81 & 0.11 & 0.26 & & & 0.20 & & & 171.3 & 2.50 & 0.03 \\
\hline
\end{tabular}




\begin{tabular}{|c|c|c|c|c|c|c|c|c|c|}
\hline & 0.82 & & 0.31 & & 0.13 & & 171.3 & 2.54 & 0.03 \\
\hline & 0.82 & 0.14 & 0.26 & & & -0.19 & 171.4 & 2.61 & 0.03 \\
\hline & 0.81 & & 0.33 & 0.16 & & -0.09 & 171.5 & 2.64 & 0.03 \\
\hline & 0.81 & & 0.26 & & 0.12 & -0.23 & 171.6 & 2.74 & 0.02 \\
\hline & 0.82 & 0.18 & & 0.20 & 0.20 & & 171.7 & 2.90 & 0.02 \\
\hline & 0.82 & 0.20 & & & 0.20 & -0.18 & 171.8 & 3.04 & 0.02 \\
\hline & 0.80 & & & 0.20 & 0.30 & -0.09 & 172.4 & 3.58 & 0.02 \\
\hline & 0.83 & 0.22 & 0.18 & & 0.10 & & 172.8 & 3.95 & 0.01 \\
\hline activity-density & -1.07 & 0.60 & & & & & 75.6 & 0 & 0.20 \\
\hline & -1.13 & & & & & -0.59 & 76.6 & 0.98 & 0.12 \\
\hline & -1.12 & 0.46 & & & & -0.37 & 76.6 & 0.98 & 0.12 \\
\hline & -1.17 & & 0.46 & & & -0.50 & 77.1 & 1.42 & 0.10 \\
\hline & -1.11 & 0.49 & & 0.25 & & & 77.6 & 1.94 & 0.07 \\
\hline & -1.13 & & & 0.54 & & & 77.6 & 1.94 & 0.07 \\
\hline & -1.10 & & 0.57 & & & & 77.7 & 2.10 & 0.07 \\
\hline & -1.09 & 0.50 & 0.19 & & & & 78.0 & 2.39 & 0.06 \\
\hline & -1.16 & & 0.45 & 0.40 & & & 78.3 & 2.66 & 0.05 \\
\hline & -1.02 & & & & & & 78.9 & 3.28 & 0.04 \\
\hline & -1.14 & 0.32 & 0.22 & & & -0.39 & 79.1 & 3.45 & 0.04 \\
\hline & -1.14 & & & 0.09 & & -0.51 & 79.2 & 3.57 & 0.03 \\
\hline & -1.11 & 0.47 & & -0.10 & & -0.45 & 79.3 & 3.71 & 0.03 \\
\hline dimorphic richness & 5.90 & & -1.45 & & & 1.00 & 220.9 & 0 & 0.10 \\
\hline & 5.90 & & -1.42 & -0.91 & & & 221.5 & 0.56 & 0.07 \\
\hline & 5.90 & & -1.42 & -0.22 & & 0.81 & 221.7 & 0.81 & 0.06 \\
\hline & 5.90 & & -1.16 & & -0.38 & 0.98 & 221.9 & 1.02 & 0.06 \\
\hline & 5.90 & & -1.68 & & & & 222.0 & 1.04 & 0.06 \\
\hline & 5.90 & 0.15 & -1.54 & & & 1.04 & 222.1 & 1.22 & 0.05 \\
\hline & 5.90 & & & & -1.25 & 1.05 & 222.5 & 1.55 & 0.04 \\
\hline & 5.90 & & -1.15 & -0.88 & -0.36 & & 222.5 & 1.58 & 0.04 \\
\hline & 5.90 & 0.17 & -1.53 & -0.96 & & & 222.6 & 1.71 & 0.04 \\
\hline
\end{tabular}




\begin{tabular}{|c|c|c|c|c|c|c|c|c|c|c|}
\hline & 5.90 & & & -1.30 & & -0.49 & & 222.7 & 1.74 & 0.04 \\
\hline & 5.90 & & & -1.15 & -0.20 & -0.37 & 0.82 & 222.9 & 1.99 & 0.04 \\
\hline & 5.90 & & -0.38 & -1.41 & & & & 222.9 & 2.02 & 0.04 \\
\hline & 5.90 & & & & -0.96 & -1.22 & & 223.0 & 2.05 & 0.03 \\
\hline & 5.90 & & 0.21 & -1.55 & -0.28 & & 0.83 & 223.0 & 2.11 & 0.03 \\
\hline & 5.90 & & & & -0.29 & -1.22 & 0.81 & 223.2 & 2.29 & 0.03 \\
\hline & 5.90 & & 0.21 & -1.27 & & -0.41 & 1.04 & 223.3 & 2.35 & 0.03 \\
\hline & 5.90 & & & & & -1.49 & & 223.6 & 2.71 & 0.03 \\
\hline & 5.90 & & 0.23 & -1.27 & -0.95 & -0.39 & & 223.8 & 2.84 & 0.02 \\
\hline & 5.90 & & -0.30 & & & -1.09 & 0.96 & 223.8 & 2.84 & 0.02 \\
\hline & 5.90 & & -0.31 & -1.12 & & -0.44 & & 223.8 & 2.91 & 0.02 \\
\hline & 5.90 & & -0.73 & & & -1.04 & & 224.1 & 3.22 & 0.02 \\
\hline & 5.90 & & -0.26 & & -0.87 & -1.09 & & 224.2 & 3.30 & 0.02 \\
\hline & 5.90 & & 0.26 & -1.28 & -0.27 & -0.40 & 0.83 & 224.3 & 3.41 & 0.02 \\
\hline & 5.90 & & -0.97 & & & & 0.92 & 224.4 & 3.45 & 0.02 \\
\hline & 5.90 & & -0.25 & & -0.21 & -1.09 & 0.80 & 224.6 & 3.72 & 0.02 \\
\hline & 5.90 & & -1.36 & & & & & 224.7 & 3.78 & 0.01 \\
\hline & 5.90 & & -0.95 & & -0.84 & & & 224.8 & 3.84 & 0.01 \\
\hline & 5.90 & & & & & & 1.32 & 224.9 & 3.97 & 0.01 \\
\hline activity-density & 0.12 & & & -0.31 & & & & 123.3 & 0 & 0.47 \\
\hline & 0.11 & & & & & & & 124.2 & 0.86 & 0.30 \\
\hline & 0.11 & 0.01 & & -0.31 & & & & 125.9 & 2.62 & 0.13 \\
\hline & 0.11 & 0.11 & & & & & & 126.3 & 2.95 & 0.11 \\
\hline macropterous richness & 2.47 & & & & & & & 265.7 & 0 & 0.36 \\
\hline & 2.47 & -0.13 & & & & & & 266.1 & 0.44 & 0.29 \\
\hline & 2.47 & & & & -0.09 & & & 267.1 & 1.40 & 0.18 \\
\hline & 2.46 & -0.15 & & & -0.12 & & & 267.2 & 1.49 & 0.17 \\
\hline activity-density & 0.84 & & & 0.34 & & & & 159.4 & 0 & 1.00 \\
\hline
\end{tabular}




\section{Appendix 2C}

Corrected Akaike information criterion $\left(\mathrm{AIC}_{\mathrm{c}}\right), \mathrm{AIC}_{\mathrm{c}}$ difference with best model $\left(\triangle \mathrm{AIC} \mathrm{C}_{\mathrm{c}}\right)$, and Akaike weights $\left(w_{i}\right)$ of all supported models $\left(\Delta \mathrm{AIC} \mathrm{C}_{\mathrm{c}}<\right.$ 4 ) that were included in model averaging for the analysis of bird biodiversity measures. Models are ordered in terms of $\triangle \mathrm{AIC}_{\mathrm{c}}$. In bold are the biodiversity measures with significant effects detected. \% PG: proportion of permanent grassland (\%), PG connect: permanent grassland connectivity index, PG LP: largest permanent grassland patch (ha), PG edges: permanent grassland edges (km), \% WH: proportion of wooded habitat (\%), WH edges: wooded habitat edges ( $\mathrm{km})$, \% crops: proportion of crop (\%)

\begin{tabular}{|c|c|c|c|c|c|c|c|c|c|c|c|c|}
\hline Biodiversity measure & 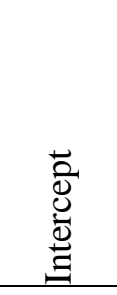 & 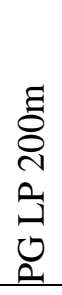 & 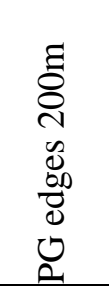 & 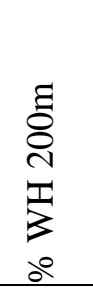 & 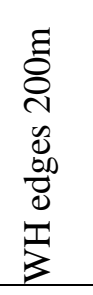 & $\begin{array}{l}\Xi \\
\delta \\
0 \\
0 \\
0 \\
0\end{array}$ & 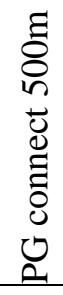 & $\begin{array}{l}\Xi \\
8 \\
0 \\
n \\
1 \\
3 \\
2\end{array}$ & $\begin{array}{l}\text { E } \\
8 \\
0 \\
0 \\
0 \\
0 \\
0 \\
0 \\
1\end{array}$ & $\mathrm{AlC}_{\mathrm{c}}$ & $\Delta \mathrm{AlC}_{\mathrm{c}}$ & $w_{i}$ \\
\hline \multirow[t]{2}{*}{ all species total richness } & 24.29 & & & & 1.18 & & & & & 118.8 & 0 & 0.55 \\
\hline & 24.29 & & & & & & & & & 119.3 & 0.44 & 0.45 \\
\hline \multirow[t]{4}{*}{ richness of nester } & 15.86 & & & & & & & & & 88.0 & 0 & 0.35 \\
\hline & 15.87 & & & 0.64 & & & & & & 88.2 & 0.24 & 0.31 \\
\hline & 15.87 & & & & 0.60 & & & & & 88.5 & 0.59 & 0.26 \\
\hline & 15.87 & & & 0.42 & 0.28 & & & & & 90.8 & 2.86 & 0.08 \\
\hline \multirow[t]{6}{*}{ abundance of nester } & 25.81 & & & 2.23 & & & & & & 115.7 & 0 & 0.28 \\
\hline & 25.81 & & & 1.42 & 1.07 & & & & & 116.2 & 0.52 & 0.21 \\
\hline & 25.81 & & & & 2.15 & & & & & 116.4 & 0.68 & 0.20 \\
\hline & 25.81 & & & 2.57 & & & & -0.47 & & 117.0 & 1.34 & 0.14 \\
\hline & 25.81 & & & 1.81 & 1.19 & & & -0.66 & & 117.8 & 2.15 & 0.09 \\
\hline & 25.81 & & & & 2.11 & & & 0.06 & & 118.1 & 2.41 & 0.08 \\
\hline \multirow[t]{4}{*}{ forest total richness } & 7.10 & & -0.82 & & & & & & & 88.2 & 0 & 0.24 \\
\hline & 7.10 & & -0.71 & & 0.60 & & & & & 89.0 & 0.82 & 0.16 \\
\hline & 7.10 & & & & 0.74 & & & & & 89.2 & 1.00 & 0.14 \\
\hline & 7.10 & & & & & & & & & 89.8 & 1.57 & 0.11 \\
\hline
\end{tabular}




\begin{tabular}{|c|c|c|c|c|c|c|c|c|c|}
\hline & 7.10 & 0.66 & & & & & 90.0 & 1.78 & 0.10 \\
\hline & 7.10 & 0.40 & -0.66 & & & & 90.7 & 2.52 & 0.07 \\
\hline & 7.10 & & -0.76 & & & 0.35 & 91.0 & 2.77 & 0.06 \\
\hline & 7.10 & & & & & 0.49 & 91.4 & 3.15 & 0.05 \\
\hline & 7.10 & 0.40 & & 0.55 & & & 91.7 & 3.48 & 0.04 \\
\hline & 7.10 & & & 0.78 & & -0.06 & 92.2 & 3.96 & 0.03 \\
\hline \multirow[t]{6}{*}{ richness of nester } & 4.38 & & & 0.88 & & & 68.9 & 0 & 0.44 \\
\hline & 4.38 & & 0.84 & & & & 70.3 & 1.40 & 0.22 \\
\hline & 4.38 & & 0.41 & 0.57 & & & 71.2 & 2.32 & 0.14 \\
\hline & 4.38 & & & 1.01 & -0.22 & & 72.5 & 3.63 & 0.07 \\
\hline & 4.38 & & & 1.01 & & -0.19 & 72.5 & 3.65 & 0.07 \\
\hline & 4.38 & & 1.12 & & -0.39 & & 72.7 & 3.83 & 0.06 \\
\hline \multirow[t]{3}{*}{ abundance of nester } & 7.43 & & 1.78 & & & & 90.4 & 0 & 0.64 \\
\hline & 7.43 & & 1.49 & 0.38 & & & 92.7 & 2.37 & 0.19 \\
\hline & 7.43 & & 1.98 & & -0.25 & & 93.0 & 2.66 & 0.17 \\
\hline \multirow[t]{8}{*}{ generalist total richness } & 10.14 & & & 0.78 & & & 73.6 & 0 & 0.44 \\
\hline & 10.14 & & 0.73 & & & & 74.7 & 1.12 & 0.25 \\
\hline & 10.14 & & & 1.09 & & -0.44 & 75.7 & 2.13 & 0.15 \\
\hline & 10.14 & & 0.34 & 0.52 & & & 76.4 & 2.81 & 0.11 \\
\hline & 10.14 & & & 0.80 & -0.03 & & 77.6 & 3.98 & 0.06 \\
\hline & 2.09 & & & & & & 90.0 & 0 & 0.62 \\
\hline & 2.08 & & & & & 0.05 & 92.4 & 2.38 & 0.19 \\
\hline & 2.08 & & & & 0.04 & & 92.5 & 2.42 & 0.19 \\
\hline \multirow[t]{7}{*}{ abundance of nester } & 14.48 & & & 1.25 & & & 97.8 & 0 & 0.33 \\
\hline & 14.48 & & 1.03 & & & & 100.0 & 2.21 & 0.11 \\
\hline & 14.48 & & 0.21 & 1.09 & & & 100.0 & 2.26 & 0.11 \\
\hline & 14.48 & & & 1.01 & 0.39 & & 100.1 & 2.29 & 0.11 \\
\hline & 14.48 & & & & 1.01 & & 100.2 & 2.40 & 0.10 \\
\hline & 14.48 & & & 1.29 & & -0.05 & 100.3 & 2.51 & 0.09 \\
\hline & 14.48 & & & & & 0.85 & 101.4 & 3.63 & 0.05 \\
\hline
\end{tabular}




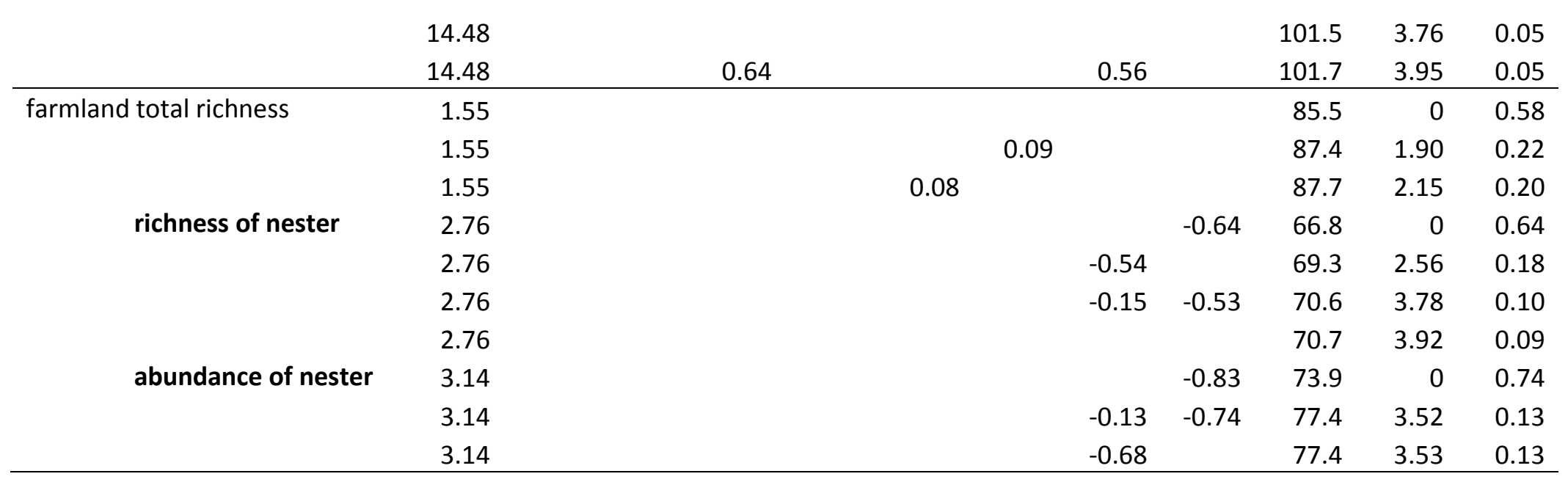

